\title{
O comportamento eleitoral dos paulistas e dos brasileiros nas eleições de 2002 e 2014
}

\author{
Maria Teresa Miceli Kerbauy \\ André Luiz Vieira Dias
}

\section{Introdução}

As eleições de 2002 e 2014 foram marcadas por serem a primeira e a quarta vez consecutiva que o Partido dos Trabalhadores conquistou a presidência do Brasil. Com quase 12 anos no comando do Poder Executivo federal - interrompidos pelo impeachment sofrido por Dilma Rousseff em 31 de agosto de 2016 -, o governo petista provocou diferentes impactos sobre o comportamento dos eleitores de todo o país. Considerando que o PT tem a sua origem vinculada ao estado de São Paulo e à região Sudeste, mas que, ao longo dos processos eleitorais, passou a ter melhor desempenho na região Nordeste do país, este artigo busca compreender quais foram as variáveis que influenciaram o comportamento dos eleitorados paulista e brasileiro nesses dois momentos específicos.

A comparação entre esses diferentes momentos apenas se tornou possível a partir da implementação do $E_{\text {seb }}{ }^{1}$ - primeira pesquisa pós-eleitoral no país, de natureza acadêmica e abrangência nacional -, composto por diversas questões socioeconômicas e conjuntos de variáveis sobre atitudes, valores políticos e voto, que nos permitem investigar de maneira sistemática como se comportam os eleitores brasileiros. Em sua primeira onda, o Eseb de 2002 entrevistou 2.513 pessoas, sendo 743 do estado de São Paulo e, em sua onda mais recente, em 2014, foram 2.506 entrevistados por todo o país, incluindo uma amostra específica de 574 entrevistados paulistas.

Nosso argumento principal é de que o comportamento do eleitorado paulista é distinto do eleitorado dos outros estados brasileiros. O eleitorado paulista tende a enfatizar razões de ordem pragmática (rejeição partidária, ser beneficiário do Bolsa

\footnotetext{
${ }^{1} \mathrm{O}$ Estudo Eleitoral Brasileiro (Eseb) é um survey nacional que serve como um excelente instrumento de acompanhamento sistemático das tendências, opiniões e transformações dos padrões comportamentais dos eleitores brasileiros. Vinculado ao survey internacional Comparative Study of Electoral Systems (CSES), o Eseb tem sido aplicado periodicamente logo após o término de cada eleição presidencial desde 2002. Esse estudo parte do pressuposto de que os contextos sociopolíticos e os arranjos institucionais influenciam a natureza e a qualidade da democracia. Dessa maneira, busca "identificar como variáveis contextuais, especialmente as instituições eleitorais, moldam crenças e comportamentos dos cidadãos e, através de eleições, definem a capacidade ou a qualidade do regime democrático; compreender a natureza dos alinhamentos e clivagens sociais e políticos; compreender como cidadãos, vivendo sob distintos arranjos políticos, avaliam os processos políticos e as instituições democráticas" (Cesop, 2011, p. 517).
} 
Família, avaliação do desempenho do governo e da economia, satisfação com o funcionamento da democracia, adesão à democracia e problemas do país) em detrimento dos aspectos identitários (autolocalização ideológica e interesse por política). O comportamento do eleitorado dos outros estados, por sua vez, é mais bem explicado por estes últimos e por fatores sociodemográficos (renda familiar mensal, escolaridade, idade, sexo e religião).

O artigo está estruturado da seguinte maneira: inicialmente, em "Teorias explicativas do voto e suas variáveis", realizamos uma revisão das principais teorias, internacionais e nacionais, que discutem os conjuntos de variáveis que explicam a decisão do voto - inclusive alguns dos estudos que se dispuseram a compreender o comportamento do eleitorado paulista; em seguida, em "Quem são os eleitores paulistas e os eleitores brasileiros?", apresentamos o perfil dos dois grupos de eleitores - quem são e como se comportam nas eleições - a partir de uma análise descritiva e pela aplicação do modelo de regressão logística sobre as variáveis dependentes: voto para presidente e para governador de São Paulo no $1^{0}$ turno das eleições de 2002 e $2014^{2}$. Na última seção, tecemos nossas "Conclusões", procurando contribuir para a identificação e a explicação de alguns aspectos e tendências do comportamento político dos eleitorados paulista e brasileiro.

\section{Teorias explicativas do voto e suas variáveis}

Somente a partir da década de 1940 os estudos eleitorais se aprimoraram e ganharam profundidade analítica. Em The people's choice, Lazarsfeld, Berelson e Gaudet (1944) aplicaram algumas técnicas para avaliar os votos dos eleitores, além de outras questões relacionadas ao seu perfil social. Depois dessa pesquisa pioneira, a organização e a aplicação de researches, surveys ou panels eleitorais se disseminaram por todo o mundo.

Entretanto, foi em The new American voter que Miller e Shanks (1996) empreenderam uma síntese de diferentes conjuntos de variáveis capazes de explicar a decisão do voto. Segundo os autores, somente uma teoria de médio alcance é capaz de perceber as diversas maneiras de pensar o comportamento eleitoral. Em linhas gerais, Miller e Shanks (1996) distinguem seis grupos de fatores que influenciam o comportamento eleitoral, organizados de maneira temporal, ou seja, perto ou longe do momento eleitoral. São eles: a) as características sociais e econômicas dos eleitores; b) as predisposições partidárias e ideológicas; c) as posições em relação a problemas de políticas públicas e avaliação da situação econômica; d) a avaliação do governo; e) a avaliação da imagem do candidato; e f) a avaliação prospectiva dos partidos e dos candidatos.

\footnotetext{
2 Optamos por analisar apenas os resultados do $1^{0}$ turno das eleições de 2002 e 2014 , pois nesse período é possível identificar de forma mais adequada as predisposições, opiniões e decisões mais latentes dos eleitorados em estudo.
} 
O primeiro conjunto de variáveis, o das características sociais e econômicas dos eleitores, consiste num modelo de fator de longo prazo ancorado, especialmente, na ideia de classe social, no qual os cidadãos votariam de acordo com a classe a que pertencem. Relacionada à questão social, esse conjunto de variáveis agrega a questão de gênero, o grau de escolaridade e urbanização, as questões étnicas, religiosas etc., todos fatores de longo prazo, uma vez que as pessoas estão vinculadas a eles desde que nasceram. Nesse sentido, os cidadãos votariam de acordo com o ambiente social a que pertencem (Lazarsfeld, Berelson e Gaudet, 1944; Lipset, 1967; Alford, 1967).

O segundo conjunto de variáveis trata das predisposições partidárias e ideológicas. Baseado nos estudos dos pesquisadores da Universidade de Michigan, seu pressuposto é de que as características econômicas e sociais passam por um filtro de natureza individual. A partir de pesquisas quantitativas, discussões de grupos monitoradas e elaboração de questionários abertos e fechados, os pesquisadores de Michigan defendem que há um tipo de processamento mais complexo na escolha eleitoral. Nesse processo, dois fatores são importantes: a identificação partidária e a identificação ideológica - ou seja, o vínculo psicológico relacionado a um determinado partido e à autolocalização ideológica (esquerda, centro ou direita) do indivíduo. Assim como o conjunto anterior, este também consiste num fator de longo prazo e importante previsor do comportamento eleitoral (Campbell et al.,1964; Converse, 1964; Nie e Andersen, 1974; Nie et al., 1976).

O terceiro conjunto é o das variáveis relativas aos problemas de políticas públicas e a avaliação da situação econômica. Fundamentadas na teoria da escolha racional, essas variáveis relacionam-se à satisfação do indivíduo no que diz respeito ao desempenho da economia e das políticas públicas do governo. Nesse caso, o eleitor é movido, ou ainda, reage, a algo do passado recente. Os teóricos da escolha racional consideram esse conjunto orientado por fatores de médio prazo, que, em conjunto com os fatores de socialização política, presentes nos conjuntos anteriores, são capazes de impactar as decisões eleitorais (Key, 1966; Popkin et al., 1976; Riker, 1983; Downs, 1957).

O quarto conjunto é o das variáveis que avaliam o desempenho dos governos. Independente do conjunto anterior, este também possui um fator de médio prazo ao considerar que o desempenho do governo é determinante para a definição do voto. Essa variável é comumente utilizada pelos surveys brasileiros para explicar a decisão do voto dos brasileiros, agindo em consonância com as variáveis dos conjuntos anteriores. Por exemplo, eleitores que se identificam com o partido governista atual tendem a avaliar positivamente tal governo e, logo, estarão mais inclinados a votar pela sua continuidade na próxima eleição.

O quinto conjunto diz respeito à variável de avaliação da imagem do candidato. Orientada por fatores de curto prazo, leva em consideração a imagem do candidato formada no período de pré-candidatura e candidatura. Os estudos de marketing político costumam destacar a importância dessa variável, sobretudo a partir das declarações que 
influenciam na construção de sua imagem pessoal. A forma como o candidato se apresenta, sobretudo na televisão e, mais recentemente, nas mídias e redes sociais, tem se mostrado importante no imaginário do eleitorado. No geral, quem decide de acordo com a imagem do candidato tende a ter menor nível de escolaridade, renda e sofisticação política. Em países com baixos índices de identidade partidária ou ideológica, tende a ser comum uma certa instabilidade provocada, em parte, pelos eleitores que votaram de acordo com a imagem dos candidatos (Lewis-Beck et al., 2008).

O sexto conjunto é o da avaliação prospectiva e retrospectiva dos partidos e dos candidatos. Nessa perspectiva, o eleitor direciona o seu olhar para o futuro ou para o retrovisor. No momento que antecede o voto, o eleitor analisa o que é mais importante: o que passou ou o que virá pela frente. Ao verificar esses critérios e aplicá-los sobre a análise dos partidos e candidaturas, o eleitor tomará a sua decisão. Esse é um importante aspecto de curto prazo que pode orientar o comportamento eleitoral (LewisBeck, 1988; Fiorina, 1981).

Em relação às variáveis que tendem a influenciar o comportamento dos brasileiros, Carreirão (2002) identificou esses cinco conjuntos de variáveis explicativas para o voto no Brasil: o voto por interesses sociais; a sofisticação política; a identificação ideológica; a tese do eleitor não racional; e o voto por avaliação de desempenho. 0 primeiro conjunto, o do voto no defensor dos interesses do povo, baseia-se na ideia de que a maioria do eleitorado tende a votar naquele candidato que para ele representa os interesses do povo, dos mais empobrecidos, dos trabalhadores. Estas seriam as teses defendidas por Singer (1990) e Castro (1994). Segundo Singer (1990), eleitores de baixa renda e escolaridade foram os responsáveis pela vitória de Collor nas eleições presidenciais de 1989. Sob um discurso populista, apresentando-se como "caçador de marajás", Collor dizia representar os interesses do povo contra os da elite. Dessa maneira, obteve o apoio das massas urbanas, influenciadas pela mídia e pela campanha eleitoral. Por outro lado, Castro (1994) atribuiu à imagem do candidato a razão para o voto naquela eleição - a imagem do defensor dos pobres, dos trabalhadores e da maioria da população.

A concepção da sofisticação política como determinante do comportamento eleitoral, também discutida por Castro (1994), parte da correlação entre as opiniões e as questões referentes a preferência partidária, posicionamento ideológico e voto. Segundo a autora, os eleitores com menor nível de sofisticação, menos informados e menos atentos ao cenário político tenderiam a se identificar com os candidatos independentemente da relação entre preferências partidárias e opiniões sobre determinados issues, ou seja, sem um sentido causal entre suas posições políticas e o voto em seu candidato.

A variável voto por identificação ideológica, assim como nos estudos internacionais elencados por Miller e Shanks (1996), também tem sido aplicada no Brasil. Nessa perspectiva, destacamos os trabalhos de Singer (1993, 1998 e 2000) que se 
baseiam na ideia de que o eleitor brasileiro orienta o seu voto a partir do contínuo esquerda-direita ou liberal-conservador, predisposição de longo prazo, além de estímulos de curto prazo, tal como representou o Plano Real nas eleições de 1994.

A perspectiva do novo eleitor não racional, tese defendida por Silveira (1996), está relacionada à influência da imagem do candidato, sobretudo dos seus atributos valorativos e simbólicos. Esse eleitor teria pouca informação e conhecimento sobre política, ideias desconexas e desarticuladas e suas decisões seriam baseadas em sua sensibilidade, intuição e emoção - "incoerente politicamente e volúvel eleitoralmente". Este seria um fenômeno internacional, em que a mídia eletrônica e o marketing político, diante do quadro de enfraquecimento dos partidos, teriam provocado um processo de personalização da política (Carreirão, 2002, p. 34).

Outra teoria explicativa é aquela que associa o resultado das urnas com a avaliação retrospectiva ou prospectiva do desempenho dos candidatos, do governo e da economia. Essas variáveis são muito recorrentes nos estudos eleitorais brasileiros, o que evidencia sua influência sobre o comportamento. Um dos casos mais lembrados é o da eleição presidencial de 1994, em que a avaliação do desempenho econômico do governo, do Plano Real, além da imagem do candidato, elegeu o presidente Fernando Henrique Cardoso (Kinzo, 1996).

O comportamento eleitoral dos paulistas tem despertado o interesse de vários pesquisadores desde a década de 1940 e durante muito tempo as pesquisas se concentraram na explicação do voto dos eleitores da capital, não levando em conta o tamanho e a importância do eleitorado do interior paulista.

O estudo pioneiro é o de Simão (1956), intitulado O voto operário em São Paulo, que, ao analisar as eleições de 1945, apontou para a existência de uma associação, em termos agregados, entre a proporção de operários e a votação obtida pelo PTB e pelo PC (que ainda estava na legalidade) nas eleições legislativas estaduais daquele ano, em cinco zonas eleitorais da capital, destacando a associação entre posição socioeconômica e voto. Considerou ainda que a passagem do rural para o urbano e as migrações internas podem ter contribuído para as atitudes e comportamentos do paulistano. Portanto, percebemos que sua análise estava em consonância com os estudos sobre comportamento eleitoral, que destacavam naquele período as influências dos fatores de socialização política, sobretudo aqueles que se relacionavam com os aspectos sociais e econômicos.

As análises publicadas por Ferreira (1960 e 1964) corroboraram com os achados de Simão, confirmando a existência de vínculos socioeconômicos com a decisão do voto e do alinhamento partidário, em São Paulo e na capital paulista.

Outra importante referência é a de Weffort (1965), que se dispôs a caracterizar o janismo e o ademarismo quanto às suas diferenças de ideologia e de posição social. Sua hipótese era a de que essas duas variáveis motivaram a decisão do eleitor paulistano nas eleições de 1962. Naquela ocasião, Weffort verificou que, quanto mais urbano e 
industrial, maiores eram as chances de vitória de Jânio Quadros, percebendo, assim, a presença de diferentes conteúdos sociais e políticos associados às figuras dos líderes. De maneira ampla, "Jânio Quadros tenderia a expressar politicamente os setores assalariados - operários e classe média assalariada - mais integrados no desenvolvimento capitalista, diversamente de Ademar de Barros, que daria expressão a camadas marginais a esse processo, em particular pequenos proprietários e setores assalariados" (Weffort, 1965, p. 51).

Em comum, os estudos citados acima apontaram para indicadores e hipóteses sobre a existência de diferenciações socioeconômicas nas bases das agremiações partidárias e do comportamento eleitoral, especialmente no apoio político às lideranças populistas do período: Ademar de Barros e Jânio Quadros (Lamounier, 1975).

Ainda sobre o período democrático de 1945-1964, uma importante referência é de Lavareda (1991), que, ao analisar a relação entre o eleitorado e os partidos políticos enquanto elemento fundamental de sustentação e legitimação do sistema político, apontou para o conceito de identificação partidária, reconhecendo sua utilidade e funcionalidade como previsor do comportamento eleitoral. A partir de dados de um survey aplicado pelo Ibope em março de 1964 em dez capitais brasileiras - dentre elas, São Paulo -, Lavareda destacou em sua análise a duração do sistema partidário, o contexto da comunicação, o quadro legal-institucional e a referência da imagem de líderes partidários. Sobre a capital paulista, Lavareda verificou que a intensidade da identificação partidária foi relativamente menor quando comparada à do Rio de Janeiro, Porto Alegre e Belo Horizonte, por exemplo. Para o autor, isso se devia "a uma série de fatores, como fortes disputas internas na seção estadual e estratégias deliberadas de esvaziamento provenientes da própria direção nacional" (Lavareda, 1991, p. 150). Para ele, a política eleitoral em São Paulo tendia a direcionamentos não partidários, sob a influência do janismo.

O crescimento do voto de oposição na cidade de São Paulo a partir de 1974 passou a ser o foco dos estudos eleitorais daquele período, indicando a tendência do voto oposicionista nos grandes centros urbanos e apontando para os contrastes entre ruralurbano e capital-interior na definição do voto.

Segundo Lamounier (1980, p. 15), "estudar o crescimento do MDB em São Paulo é o mesmo que estudar um processo de conversão do voto urbano em voto oposicionista e deste por sua vez em voto emedebista".

A literatura do período considera que, a partir da eleição de 1974, o voto urbano, por ser produto de uma estrutura social mais complexa e dinâmica, passa a ter uma importância cada vez maior nas análises sobre comportamento eleitoral em São Paulo, especialmente na capital ${ }^{3}$.

\footnotetext{
${ }^{3}$ Schwartzman (1982, p. 9), ao analisar a longa tradição autoritária do país, considera que o entendimento da vida política brasileira, no período autoritário, "passa necessariamente pela análise das contradições entre o centro econômico e mais organizado da 'sociedade civil' do país, localizado em São Paulo, e o núcleo do poder central, muito mais fixado no eixo Rio de Janeiro-Brasília". O autor considera que, "se
} 
A reforma partidária de 1979 e a eleição de 1982 atenuam o dualismo entre oposição e situação dos anos de 1970. As eleições de 1985, na competição para a prefeitura de São Paulo, com a vitória de Jânio Quadros, marcam uma rearticulação das forças políticas e redistribuição do eleitorado paulistano, produzindo profundas alterações no seu comportamento eleitoral. As análises sobre os resultados eleitorais passam a se concentrar nas eleições para o Executivo, procurando explicar a ascensão do voto de direita e a perda da hegemonia emedebista na cidade de São Paulo (Pierucci e Lima, 1991, 1993; Pierucci, 1989).

Segundo Figueiredo et al. (2002, p. 155), no período de 1982 a 1992 "não há propriamente um crescimento da direita no período, mas o crescimento e a consolidação do malufismo: a viabilidade e o sucesso de apresentar um candidato que unifique esse eleitorado. Já os votos de centro-esquerda, controlados pelo PMDB até 1982, sofrem um processo de acentuada fragmentação. O PMDB desaparece do mapa eleitoral da cidade, e as votações do PSDB e do PT apresentam muita flutuação ao longo do período".

Começava a se delinear em São Paulo uma disputa entre os três polos clássicos do espectro ideológico, esquerda, centro e direita (PT, PSDB e PDS-PP). Segundo Limongi e Mesquita (2008, p. 50), "os três polos contam com uma base de apoio que lhes permite pleitear com sucesso a cadeira de prefeito. No entanto, inexiste um bloco hegemônico. Assim as vitórias passaram a ser ditadas por coalizões entre os eleitores de diferentes blocos".

Apesar das análises que apontavam a modernização e a urbanização do país como fatores importantes para o desaparecimento das bases sociais do voto de direita, foi possível verificar que, nas eleições de 1985 para a prefeitura de São Paulo, houve a recuperação eleitoral do PDS-PP e o crescimento de um eleitorado de direita. Começou a se consolidar a percepção de um eleitorado paulistano de direita que alcança o seu ápice na eleição de 1992, quando Maluf, considerado o herdeiro do "janismo", foi eleito para prefeito de São Paulo. Apesar de Maluf ter elegido o seu sucessor, Celso Pitta, em 1996, teve início o declínio do PDS-PP e a ascensão do PSDB, que inicialmente competia pelos votos do centro do PMDB.

Ao analisarem esse contexto, Balbachevsky e Holzhacker (2004) afirmaram que, nas eleições para prefeito de São Paulo em 1996, as variáveis que influenciaram a decisão dos paulistanos estavam relacionadas à expectativa que tinham sobre o desempenho no governo do candidato apoiado por Maluf. Ou seja, sobre a capacidade que Pitta teria de realizar os objetivos desejados pelos eleitores, apontando para um voto prospectivo e pragmático.

Segundo Limongi e Mesquita (2008, p. 66), apesar da alternância entre direita e esquerda no período de 1988 a 2000 (PSDB e PT) e o esfacelamento do PMDB, não é

formas embrionárias de representação política existiram no Brasil, elas chegaram a se concentrar em São Paulo. Elas nunca chegaram a ser suficientemente fortes para moldar o quadro político nacional, mas foram suficientemente significativas para manter o estado de São Paulo como uma entidade politicamente diferenciada dentro do país" (Schwartzman, 1975, p. 23-24). 
adequado falar em fortalecimento da direita, uma vez que "são os eleitores do centro que decidem as eleições, inclinando-se ora à direita, ora à esquerda".

O quadro de alternância partidária nas eleições para a prefeitura de São Paulo entre as três forças políticas do estado não se repete nas eleições estaduais, quando o PSDB venceu todas as eleições de 1994 até 2014. As análises sobre o comportamento eleitoral da capital paulista passaram a ser estendidas para o estado como um todo, apesar de não existir uma reflexão mais aprofundada sobre o voto do eleitorado paulista. Acrescenta-se a essa questão o fato de o comportamento eleitoral de São Paulo passar a ser analisado quase que exclusivamente a partir das eleições presidenciais (1989) e a ideia de que a disputa entre PT e PSDB estruturou e organizou as demais disputas eleitorais (Limongi e Cortez, 2010).

Em linhas gerais, os estudos sobre o comportamento eleitoral de paulistas e/ou paulistanos tenderam a destacar a influência do voto urbano versus o voto rural, a representação de interesses sociais (aspectos socioeconômicos e alinhamentos partidários), a ideologia e a posição social, o voto da capital versus o do interior, o malufismo, o ademarismo, o janismo ${ }^{4}$ e o alinhamento esquerda-direita. No entanto, percebemos que a perspectiva do voto pragmático, já bastante aplicada sobre o caso brasileiro, foi pouco utilizada nas análises sobre o comportamento eleitoral dos paulistas.

Segundo Albuquerque (1992), a ascensão do voto pragmático no Brasil se deu a partir do fim da década de 1980 e início da década de 1990 - período que, em sua análise, teria sido marcado pelo declínio do voto de classe e pela ascensão de variáveis pragmáticas na explicação do voto do brasileiro. Em sua concepção, apesar de renda e escolaridade serem variáveis fáceis de observar, estas não mais explicariam o comportamento eleitoral no Brasil. Em seu lugar, a identidade, a oposição e a expectativa de desempenho começaram a influenciar a decisão do voto, uma vez que nesta os eleitores teriam passado a priorizar as melhorias necessárias prometidas pelo candidato, o combate aos inimigos do país, o que melhor representa seus interesses ou aquele que apresenta condições para derrotar um outro candidato.

Albuquerque (1992) acionou a teoria da escolha racional ao relacionar a decisão do voto à ideia de maximização de benefícios. Em sua visão, o voto por oposição também implicaria um cálculo para combater aquele candidato que, se acredita, não tem condições de trazer benefícios ao eleitor. Ao contrário do que se pudesse imaginar, o voto por oposição não se aproximaria do voto de classe, pois não estaria ancorado numa discussão ideológica, mas, sim, pragmática, podendo ser tanto retrospectiva quanto prospectiva.

A análise da influência de variáveis pragmáticas sobre o comportamento dos eleitorados paulista e brasileiro consiste em um dos objetivos deste artigo, que apresentamos a seguir.

\footnotetext{
${ }^{4}$ O malufismo, o ademarismo e o janismo compreendidos como representantes do populismo em São Paulo.
} 


\section{Quem são os eleitores paulistas e os eleitores brasileiros?}

Para compararmos o comportamento dos eleitores paulistas em relação ao dos eleitores brasileiros, isolamos os dados referentes ao estado de São Paulo e aplicamos o modelo de regressão logística binária sobre duas variáveis dependentes: os votos para presidente e para governador de São Paulo no 10 turno de 2002 e de 2014. As variáveis previsoras foram divididas em três grupos: variáveis de ordem sociodemográfica (renda familiar mensal, escolaridade, idade, sexo e religião), identitária e de interesse por política (autolocalização ideológica e interesse por política) e variáveis pragmáticas (rejeição partidária, ser beneficiário do Programa Bolsa Família ${ }^{5}$, avaliação do desempenho do governo, avaliação da situação econômica do país, satisfação com o funcionamento da democracia, adesão à democracia e apontamento do maior problema do país). A partir dessas variáveis buscamos identificar aquelas que melhor explicam o comportamento eleitoral dos paulistas e dos brasileiros de outros estados. Todavia, antes da análise dos efeitos das variáveis sobre o comportamento, realizamos a análise descritiva do perfil dos eleitores paulistas e dos de outros estados brasileiros nas eleições em estudo.

Em 2002, os paulistas possuíam maior renda familiar mensal em comparação aos brasileiros dos outros estados: enquanto no estado de São Paulo $50,9 \%$ dos respondentes possuíam renda familiar de dois a dez salários mínimos, no Brasil a maior concentração, 47,9\%, estava entre aqueles que dispunham de um a cinco salários mínimos. Em 2014, São Paulo e o Brasil em geral tenderam a concentrar o maior percentual entre as faixas de renda de 1 a 5 salários mínimos - 68,1\% e 62,5\%, respectivamente (ver o Gráfico 1 ).

\footnotetext{
${ }^{5}$ Essa variável foi aplicada apenas no Eseb de 2014, uma vez que se refere a um programa social implementado a partir da Lei Federal no 10.836 de 9 jan. 2009.
} 
Gráfico 1

Faixa de renda familiar mensal - Brasil e São Paulo - 2002 e 2014 (\%)

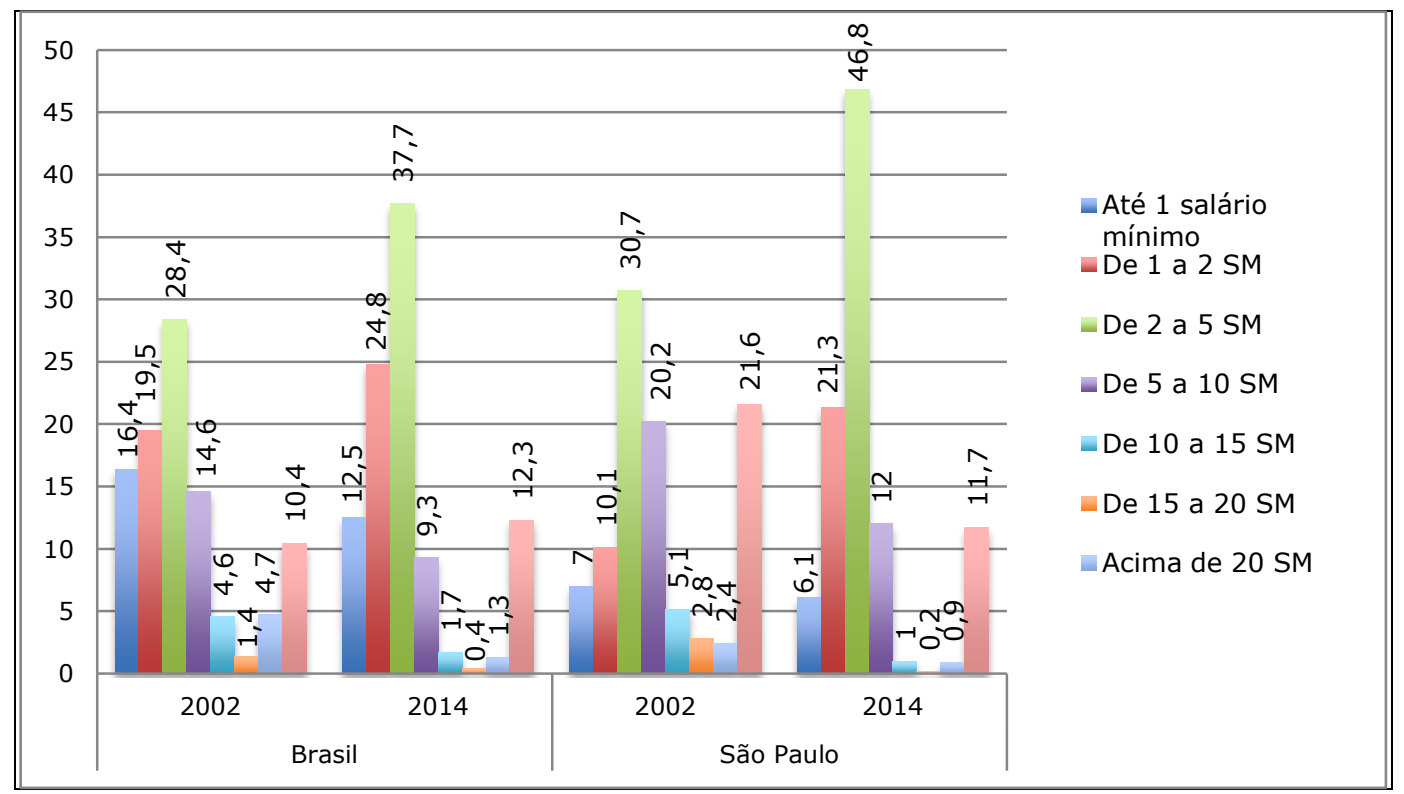

Fonte: Eseb 2002 e 2014.

Em relação aos níveis de escolaridade, em 2002, 50,8\% dos paulistas tinham entre o ensino médio e o ensino superior completo, enquanto a média nacional foi de $44,0 \%$. Em 2014, os números aumentaram para $57,4 \%$ entre os paulistas e $50,3 \%$ entre os demais brasileiros, como podemos verificar no Gráfico 2.

Gráfico 2

Nível de escolaridade - Brasil e São Paulo - 2002 e 2014 (\%)

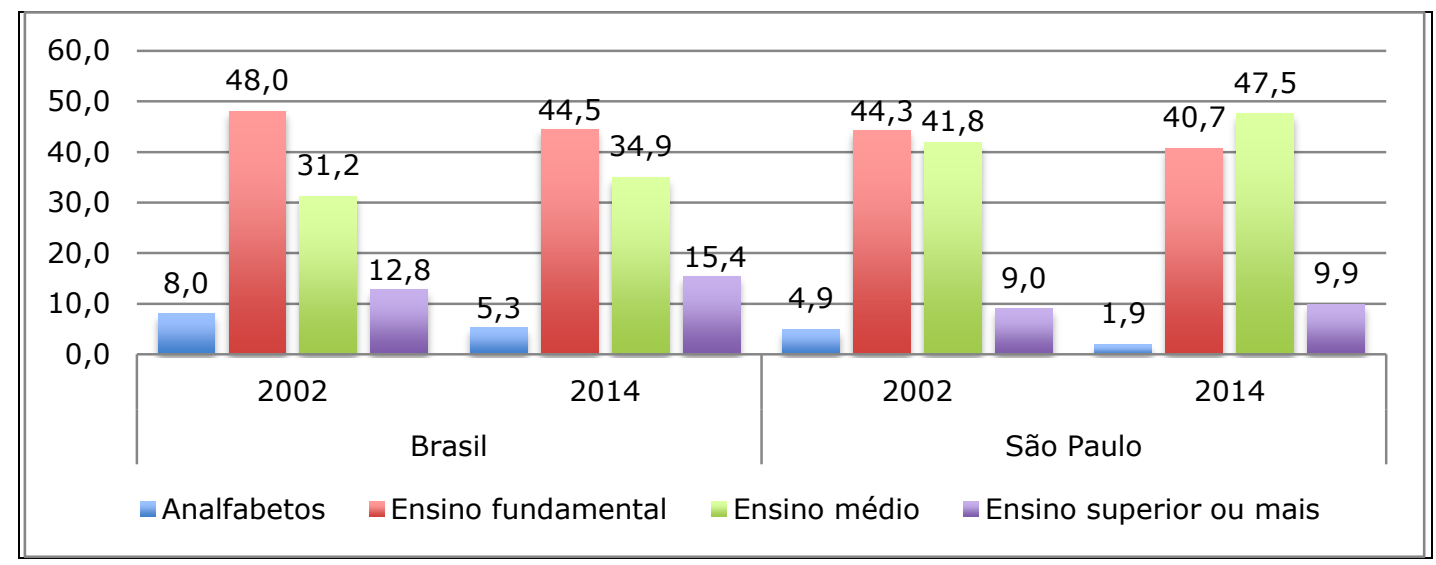

Fonte: Eseb 2002 e 2014. 
De 2002 para 2014, observamos um fenômeno comum entre os eleitorados paulista e brasileiro: a redução da população da faixa etária de 26 a 40 anos e o aumento da faixa etária de 41 a 64 anos. Nesse processo, os paulistas que eram, em média, mais jovens em 2002, tornaram-se mais velhos que a média nacional em 2014.

\section{Gráfico 3}

Faixa etária - Brasil e São Paulo - 2002 e 2014 (\%)

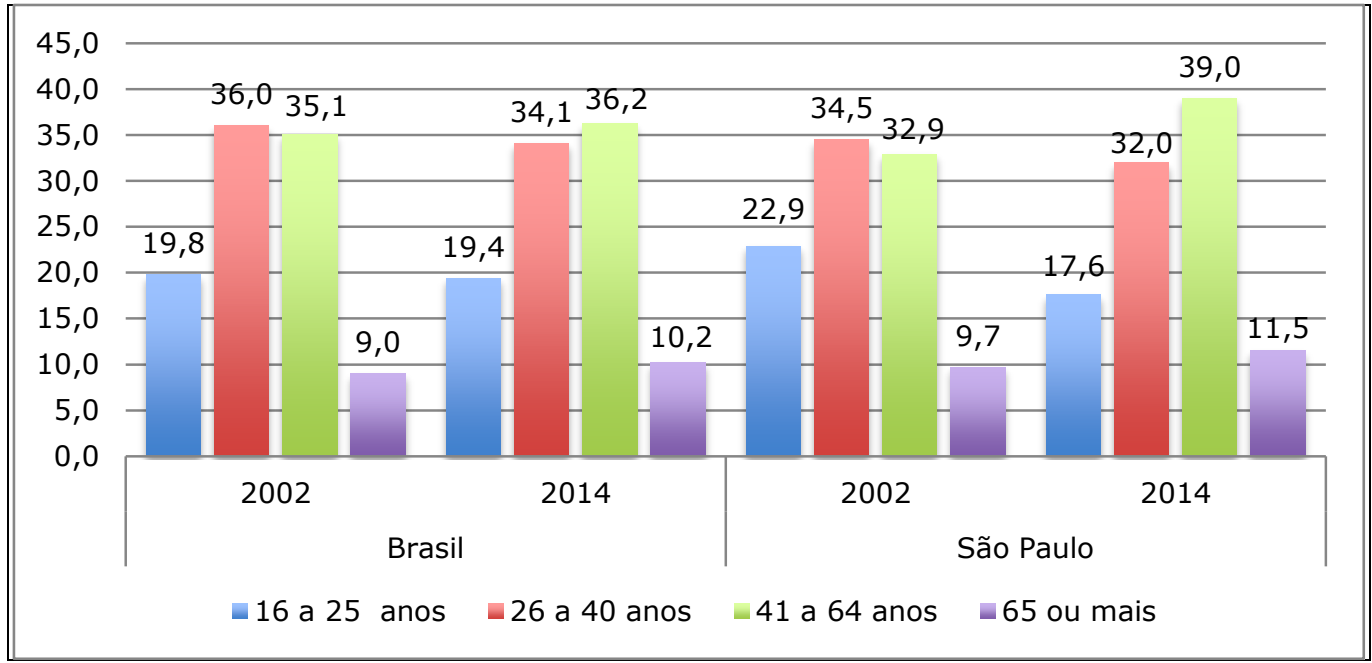

Fonte: Eseb 2002 e 2014.

Com relação à distribuição por sexo, observamos a redução da diferença da população de homens em relação à de mulheres em São Paulo entre 2002 e 2014. Embora as mulheres continuem sendo maioria, o percentual de homens aumentou na amostra paulista do Eseb de 2014.

Gráfico 4

Sexo - Brasil e São Paulo - 2002 e 2014 (\%)

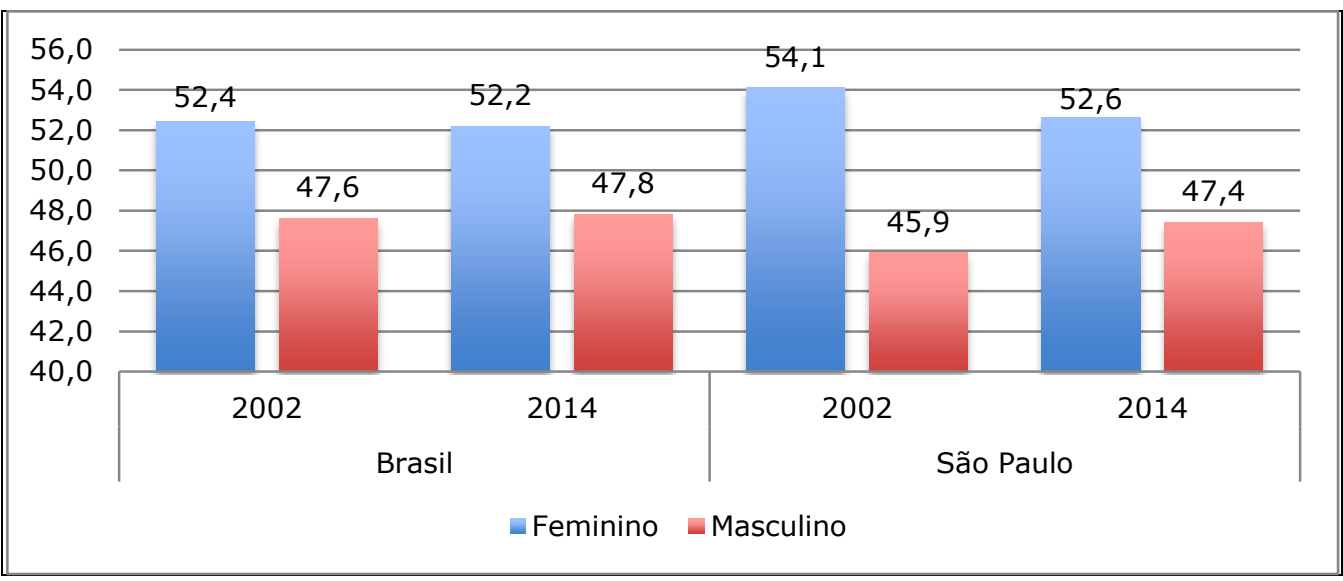

Fonte: Eseb 2002 e 2014. 
Outro processo visível nos dados é o encolhimento da proporção de católicos e o aumento de evangélicos entre 2002 e 2014, em São Paulo e no Brasil. Vale destacar que o número de católicos em São Paulo já era menor que a média nacional em 2002 e caiu ainda mais em 2014. O inverso ocorreu entre os evangélicos paulistas, que já eram proporcionalmente maiores em relação à média nacional e aumentaram em 2014.

Tabela 1

Religião - Brasil e São Paulo - 2002 e 2014

\begin{tabular}{|c|c|c|c|c|c|c|c|c|}
\hline \multirow{3}{*}{ Religião } & \multicolumn{4}{|c|}{ Brasil } & \multicolumn{4}{|c|}{ São Paulo } \\
\hline & \multicolumn{2}{|c|}{2002} & \multicolumn{2}{|c|}{2014} & \multicolumn{2}{|c|}{2002} & \multicolumn{2}{|c|}{2014} \\
\hline & $\mathbf{N}$ & $\%$ & $\mathbf{N}$ & $\%$ & $\mathbf{N}$ & $\%$ & $\mathbf{N}$ & $\%$ \\
\hline Budista & 6 & 0,4 & 1 & 0,1 & 3 & 0,4 & 3 & 0,6 \\
\hline Candomblé & 9 & 0,5 & 20 & 1,1 & 3 & 0,4 & 4 & 0,8 \\
\hline Católica & 1268 & 77,2 & 1237 & 68,1 & 485 & 70,8 & 330 & 62,6 \\
\hline Espírita kardecista / Espiritualista & 49 & 3,0 & 39 & 2,1 & 26 & 3,8 & 16 & 3,0 \\
\hline Evangélica & 244 & 14,9 & 452 & 24,9 & 131 & 19,2 & 147 & 27,8 \\
\hline Judaica & 0 & 0,0 & 0 & 0,0 & 0 & 0,0 & 0 & 0,0 \\
\hline Mórmon / Adventista / Testemunha de Jeová & 38 & 2,3 & 10 & 0,5 & 17 & 2,5 & 3 & 0,6 \\
\hline Santo Daime / Esotérica / Outras & 19 & 1,2 & 22 & 1,2 & 12 & 1,8 & 4 & 0,8 \\
\hline $\begin{array}{l}\text { Seicho No Iê / Messiânica / Perfeita } \\
\text { Liberdade }\end{array}$ & 2 & 0,1 & 0 & 0,0 & 6 & 0,9 & 1 & 0,2 \\
\hline Umbanda & 7 & 0,3 & 3 & 0,2 & 1 & 0,1 & 4 & 0,8 \\
\hline Ateu / Agnóstico / Não acredita em Deus & 1 & 0,1 & 33 & 1,8 & 1 & 0,1 & 15 & 2,8 \\
\hline Total & $1643 *$ & 100,0 & $1817 *$ & 100,0 & 685 & 100,0 & 527 & 100,0 \\
\hline
\end{tabular}

Fonte: Eseb 2002 e 2014.

* Nesta análise foram desconsiderados os casos de NR (não respondeu) e NS (não sabe).

No que diz respeito ao interesse por política, observamos que os paulistas parecem ser menos interessados do que a média dos brasileiros. Isso porque, em 2002 o percentual de paulistas que manifestaram muito interesse por política foi de $9,4 \%$ e o de brasileiros foi de $11,9 \%$. No outro extremo, entre os que disseram não ter nenhum interesse por política, os paulistas somaram 39,7\% e os brasileiros 39,4\%. Naquele ano, a maior concentração, tanto do eleitorado paulista quanto do brasileiro, foi a dos que disseram ter um pouco de interesse por política. Já em 2014, embora tenha havido um aumento significativo dos que declararam ter interesse ou um pouco de interesse por política, o percentual de paulistas muito interessados foi de apenas 3,4\% e o da média dos estados brasileiros foi de 9,4\%. Dentre aqueles que disseram não ter interesse por política encontramos $34,0 \%$ do eleitorado paulista e $25,3 \%$ do brasileiro. Ou seja, esses 
números reafirmam que o eleitorado paulista tende a ser menos interessado por política que a média do eleitorado dos outros estados brasileiros (ver o Gráfico 5).

Gráfico 5

Interesse por política - Brasil e São Paulo - 2002 e 2014 (\%)

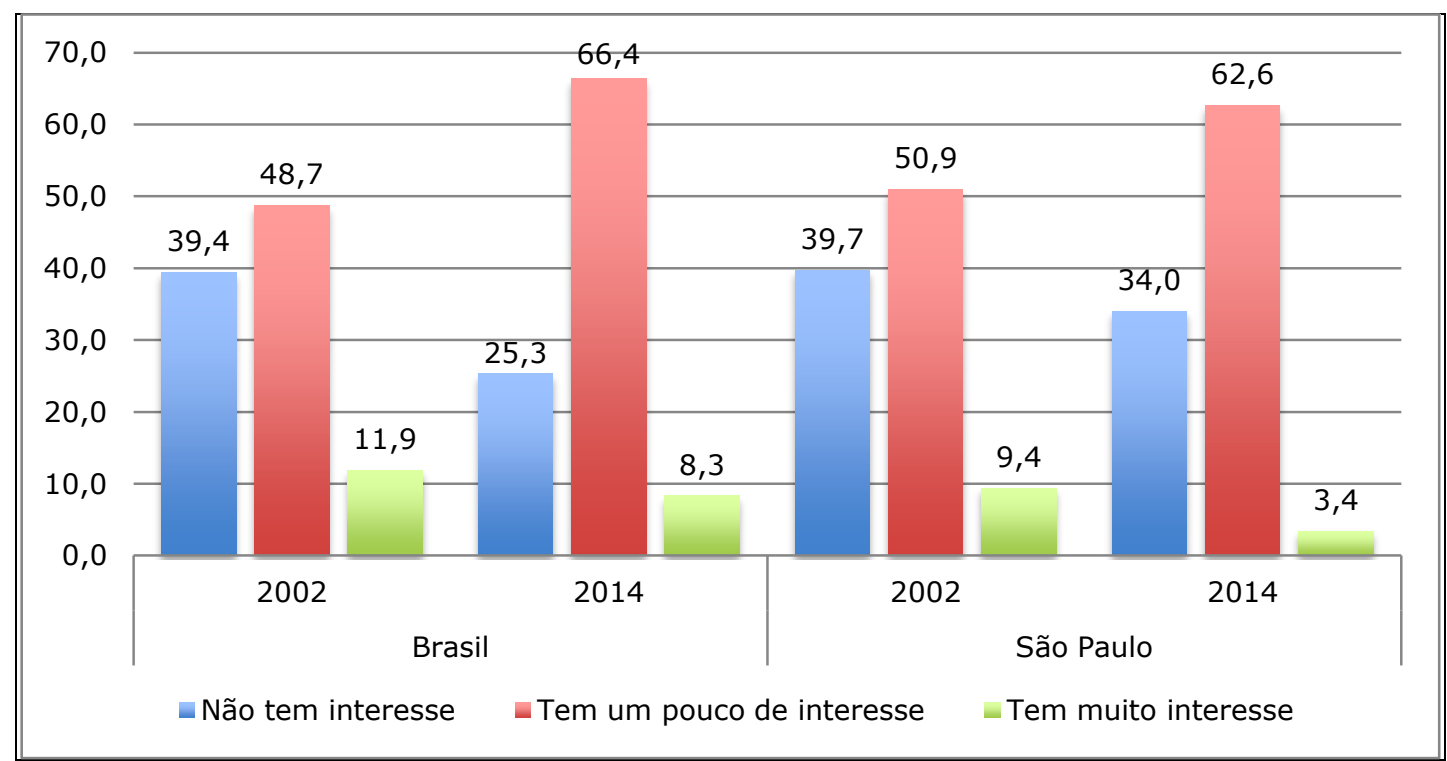

Fonte: Eseb 2002 e 2014.

Obs.: Somente respostas válidas.

Quanto à autolocalização ideológica dos entrevistados, observamos que, entre 2002 e 2014, houve uma tendência comum entre os eleitorados paulista e brasileiro de aumento daqueles que se autolocalizaram como sendo de centro e de direita e uma diminuição dos que se identificaram como de esquerda. Ou seja, embora já compusessem a maioria em 2002, o centro e a direita aumentaram ainda mais os seus percentuais em 2014 no Brasil em geral (ver o Gráfico 6).

\footnotetext{
6 A onda do Eseb de 2002 apresentou duas questões para mensurar a autolocalização ideológica do eleitorado baseadas numa escala de 0 a 10: na primeira delas, o 0 representava ser de esquerda e o 10 ser de direita; na outra, seguiu-se o sentido oposto, em que o 0 significou ser de direita e o 10 ser de esquerda. Todavia, apenas o primeiro formato foi repetido nas ondas que se seguiram e, como a nossa análise possui uma perspectiva comparativa, utilizamos apenas o modelo da escala em que 0 significa ser de esquerda e o 10 ser de direita. Ainda, para a categorização em três grupos, consideramos os que se autolocalizaram de 0 a 3 como esquerda, de 4 a 6 como de centro e de 7 a 10 como de direita.
} 


\section{Gráfico 6}

Autolocalização ideológica do eleitorado - Brasil e São Paulo - 2002 e 2014 (\%)

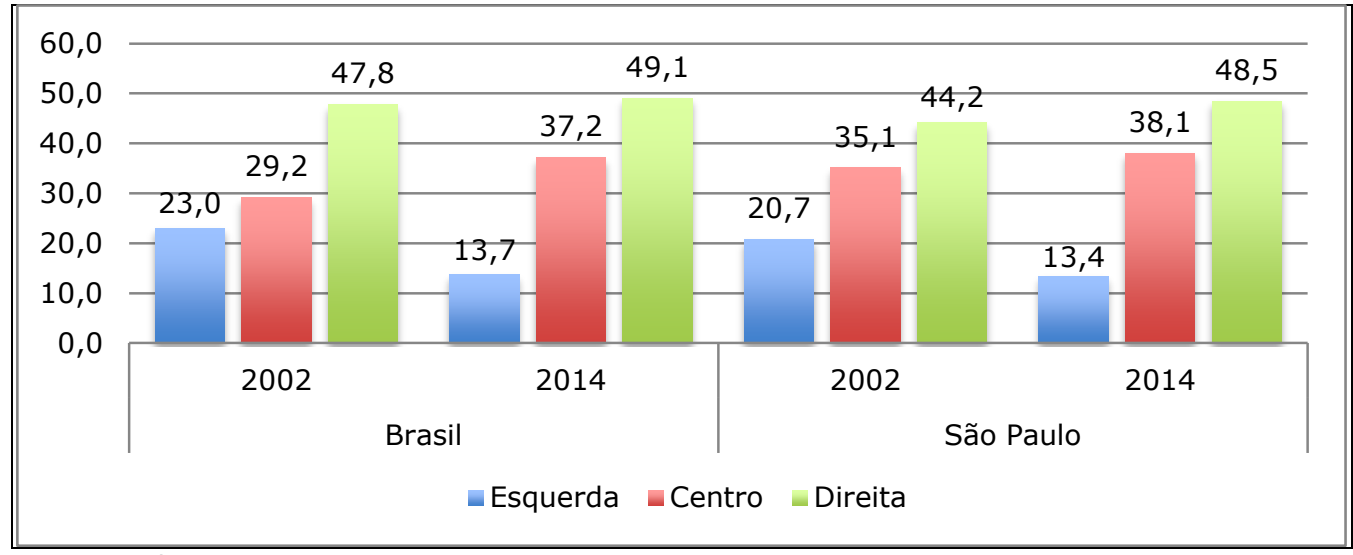

Fonte: Eseb 2002 e 2014.

Obs.: Somente respostas válidas.

No conjunto das variáveis pragmáticas, a amostra do Eseb 2014 dispôs de 18,7\% de paulistas e 33,0\% de brasileiros que afirmaram ter sido, ou ter alguém da mesma casa, beneficiado pelo Programa Bolsa Família nos últimos três anos. Mais adiante, na próxima seção, "Como se comportaram os eleitores paulistas e os eleitores brasileiros?", poderemos verificar se ter sido beneficiado por um dos principais programas sociais do governo petista influenciou a opinião e o comportamento eleitoral em 2014 (ver Gráfico 7).

\section{Gráfico 7}

Beneficiário do Programa Bolsa Família - Brasil e São Paulo - 2014 (\%)

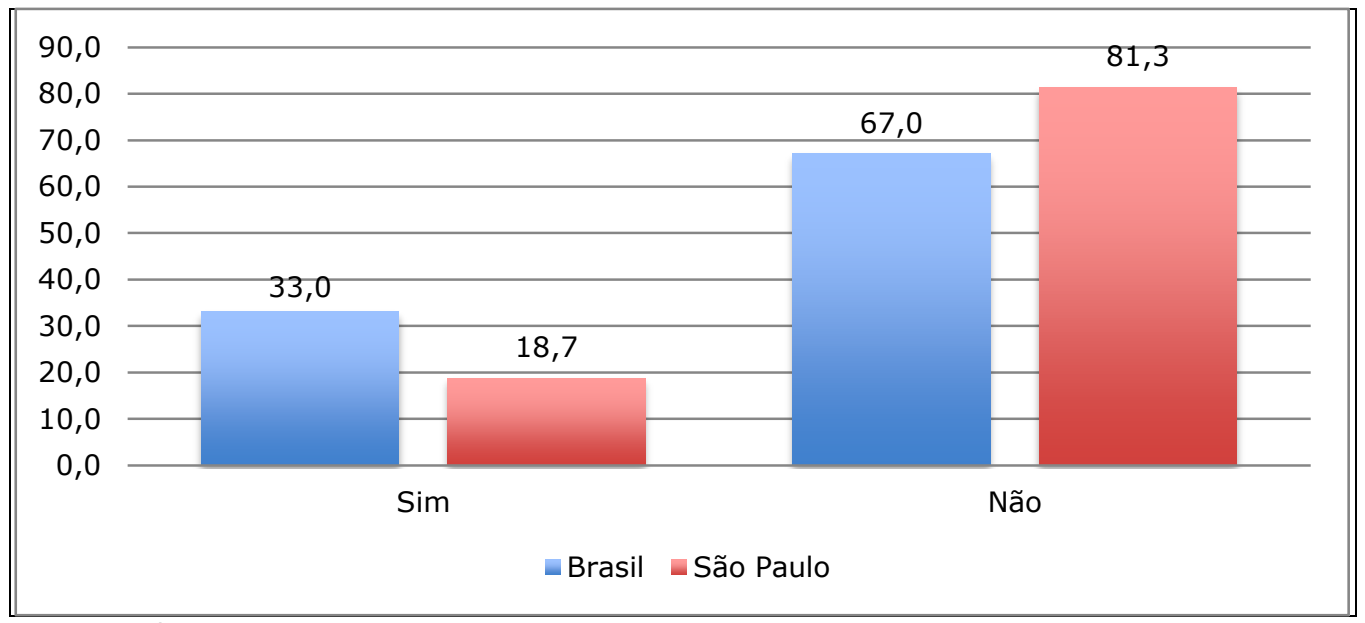

Fonte: Eseb 2002 e 2014. 
Em relação à rejeição partidária, o Gráfico 8 descreve que os eleitorados paulista e brasileiro tenderam a rejeitar tanto o PT - este em maior escala - quanto o PSDB. No entanto, em 2014, o percentual de rejeição ao PT foi consideravelmente maior em São Paulo $(43,5 \%)$ do que na média dos estados brasileiros $(35,3 \%)$. Naquele ano, a rejeição ao PSDB foi de $39,4 \%$ entre os eleitores paulistas e de $43,3 \%$ entre os brasileiros. É preciso salientar que esse cenário de aumento da rejeição partidária é evidente mesmo quando o questionário do Eseb 2014, sob o formato de escala de 0 a 10, nos permitiu mensurar a intensidade do sentimento dos respondentes. 0 impacto dessa rejeição poderá ser verificado na seguinte seção.

Gráfico 8

Rejeição partidária ao PT e ao PSDB - Brasil e São Paulo - 2002 e 2014 (\%)

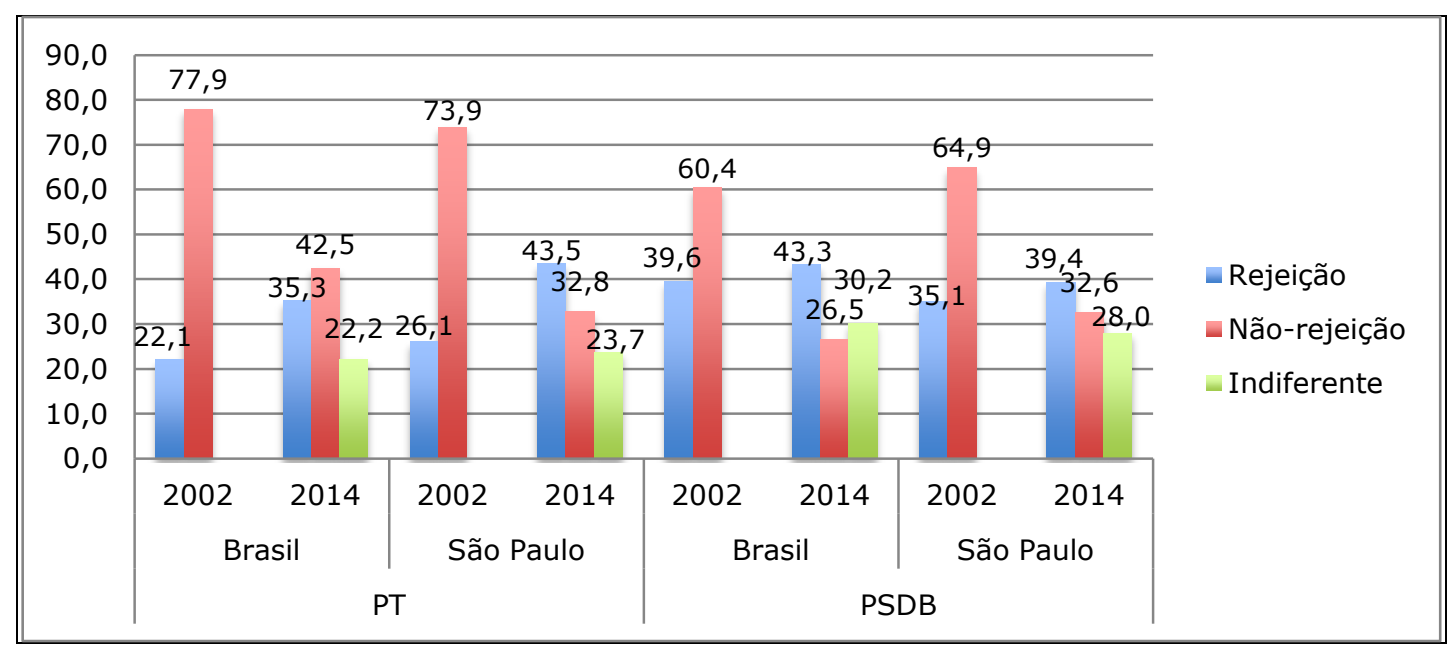

Fonte: Eseb 2002 e 2014.

Obs.: Somente respostas válidas.

As variáveis sobre a satisfação com o funcionamento da democracia e sobre a adesão à democracia têm despertado o interesse de muitos estudiosos, sobretudo a partir da teoria de Norris (1998) sobre o cidadão crítico - um indivíduo politicamente sofisticado, apoiador da democracia, mas cético em relação às instituições políticas. O Gráfico 9 demonstra que os eleitorados paulista e brasileiro pareciam nada ou pouco satisfeitos em 2002 e passaram a estar mais satisfeitos ou indiferentes em 2014. Todavia, notamos que, comparados ao eleitorado brasileiros, os eleitores paulistas estavam mais insatisfeitos com o funcionamento da democracia em 2002 e tornaram-se mais satisfeitos que a média nacional em 2014. 


\section{Gráfico 9 \\ Satisfação com o funcionamento da democracia Brasil e São Paulo - 2002 e 2014 (\%)}

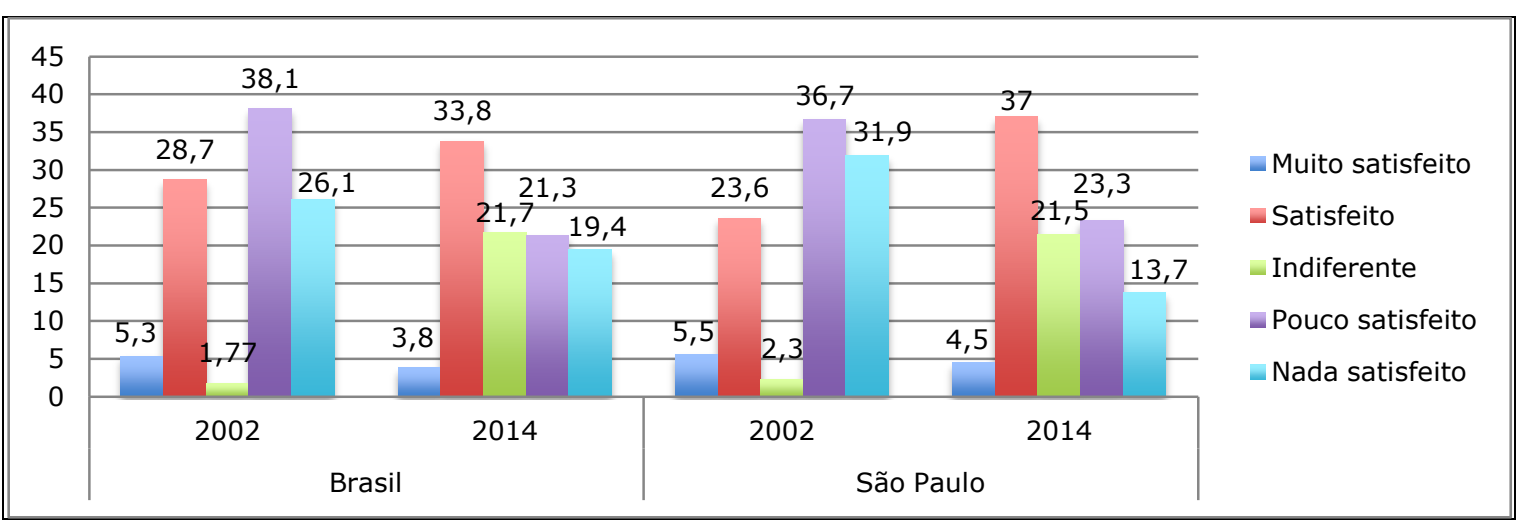

Fonte: Eseb 2002 e 2014.

Obs.: Somente respostas válidas.

No mesmo sentido, a adesão à democracia parece ter se mantido estável nos anos de 2002 e 2014, tanto entre paulistas como na média dos estados brasileiros. Dentre as possíveis análises dos resultados apresentados no Gráfico 10, verificamos a redução do apoio à ideia de que, em algumas situações, a ditadura é a melhor forma de governo em relação à democracia. Todavia, vale salientar que a opção "indiferente" só passou a compor o questionário do Eseb em 2014 (ver Gráfico 10).

Gráfico 10

\section{Adesão à democracia - Brasil e São Paulo - 2002 e 2014 (\%)}

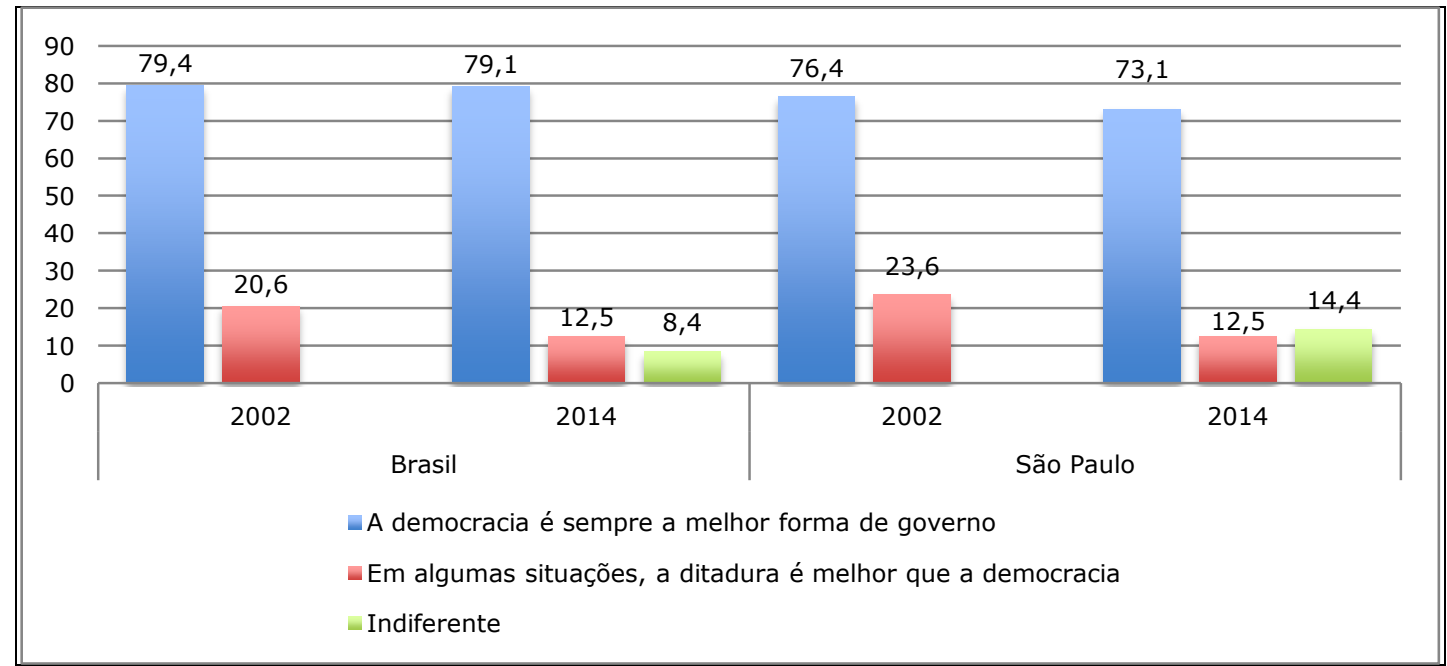

Fonte: Eseb 2002 e 2014.

Obs.: Somente respostas válidas. 
A avaliação retrospectiva do governo costuma ser muito utilizada nos estudos eleitorais brasileiros por se tratar de uma variável pragmática capaz de definir a escolha do voto. Ao olharem para o retrovisor, os eleitores avaliam se o governo foi bom o suficiente e se merece um voto de confiança para a sua continuidade. Dentre as possíveis leituras do Gráfico 11, destacamos as diferenças entre paulistas e brasileiros acerca da avaliação do governo Fernando Henrique Cardoso em 2002 e do governo Dilma em 2014. O eleitorado paulista foi mais crítico aos governos de Fernando Henrique Cardoso e de Dilma, especialmente em 2014, quando 49,7\% da média dos brasileiros avaliaram como ótimo e bom o governo Dilma, enquanto $32,8 \%$ dos paulistas o avaliaram da mesma forma.

Gráfico 11

Avaliação retrospectiva dos governos FHC e Dilma Brasil e São Paulo - 2002 e 2014 (\%)*

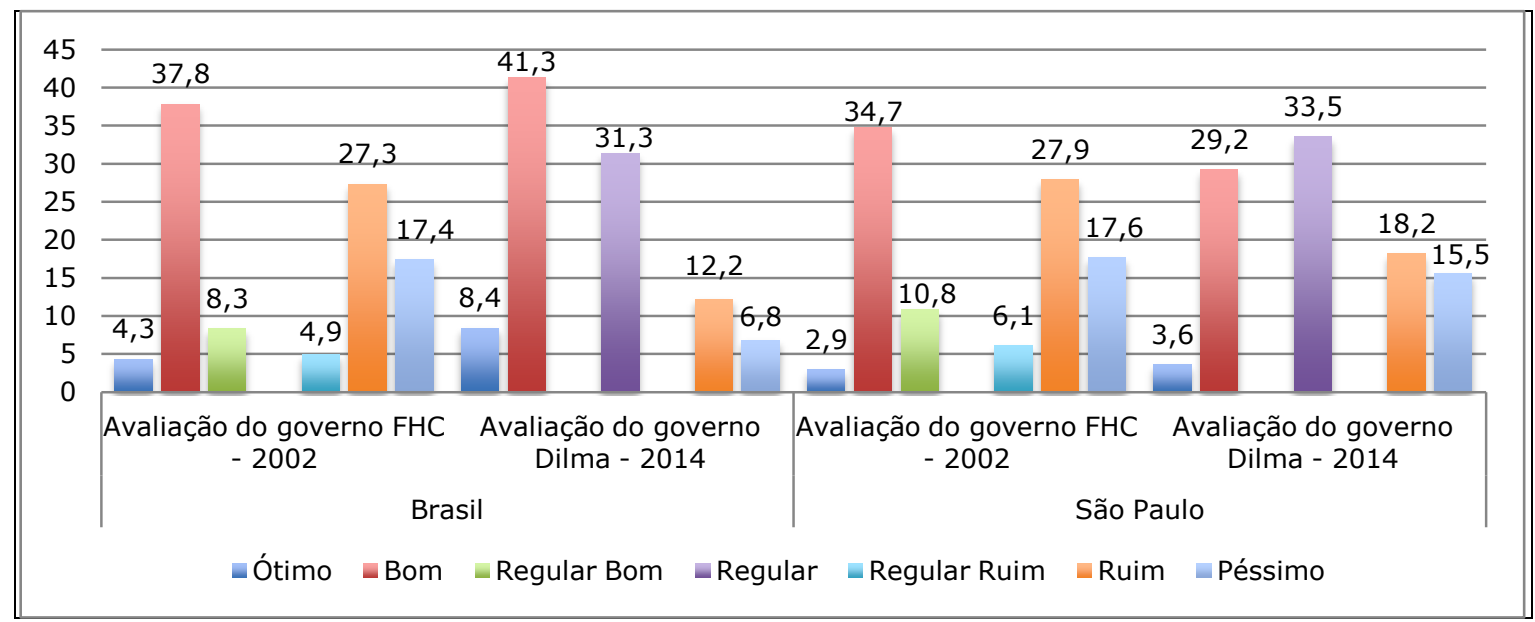

Fonte: Eseb 2002 e 2014.

Obs.: Somente respostas válidas.

* Em 2002, as respostas à pergunta sobre avaliação do governo eram: Ótimo, Bom, Regular para bom, Regular para ruim, Ruim e Péssimo. Em 2014, as respostas foram: Ótimo, Bom, Regular, Ruim e Péssimo.

A variável que mensura os maiores problemas do país também tende a influenciar o voto no mesmo sentido que a variável anterior. Em 2002, tanto em São Paulo como nos demais estados brasileiros, os quatro problemas mais apontados pelo Eseb foram desemprego, violência/segurança, inflação e fome/pobreza/miséria - com distintas intensidades ${ }^{7}$ (ver a Tabela 2).

\footnotetext{
${ }^{7}$ A questão sobre o maior problema do Brasil não foi aplicada pelo Eseb em 2014. Todavia, consideramos importante sua inclusão em nossa análise sobre o comportamento eleitoral em 2002, sobretudo pela indicação de Holzhacker e Balbachevsky (2007), que apontaram para o voto pragmático dos brasileiros naquele momento.
} 
Tabela 2

Maior problema do Brasil - Brasil e São Paulo - $2002(\%)^{8}$

\begin{tabular}{|c|c|c|c|c|}
\hline \multirow{2}{*}{ Maior problema do Brasil } & \multicolumn{2}{|c|}{ Brasil } & \multicolumn{2}{|c|}{ São Paulo } \\
\hline & $\mathbf{N}$ & $\%$ & $\mathbf{N}$ & $\%$ \\
\hline Desemprego & 583 & 36,0 & 338 & 46,7 \\
\hline Violência / Segurança & 224 & 13,8 & 115 & 15,9 \\
\hline Inflação & 206 & 12,7 & 53 & 7,3 \\
\hline Corrupção & 33 & 2,0 & 19 & 2,6 \\
\hline Educação & 45 & 2,8 & 11 & 1,5 \\
\hline Saúde & 55 & 3,4 & 22 & 3,1 \\
\hline Fome / Pobreza / Miséria & 161 & 9,9 & 64 & 8,8 \\
\hline Desigualdade social / Distribuição de renda & 50 & 3,1 & 14 & 1,9 \\
\hline Salários / Poder aquisitivo & 68 & 4,2 & 24 & 3,3 \\
\hline $\begin{array}{l}\text { Economia / Dólar / Crise econômica / Juros } \\
\text { altos }\end{array}$ & 59 & 3,6 & 26 & 3,6 \\
\hline Governo FHC / Políticas adotadas & 27 & 1,7 & 6 & 0,8 \\
\hline Drogas & 8 & 0,5 & 2 & 0,3 \\
\hline Dívida externa & 12 & 0,7 & 4 & 0,6 \\
\hline Má administração / Políticos & 9 & 0,6 & 0 & 0,0 \\
\hline Seca & 4 & 0,3 & 0 & 0,0 \\
\hline Transporte & 2 & 0,1 & 3 & 0,4 \\
\hline Desvalorização do Real & 4 & 0,2 & 2 & 0,3 \\
\hline Impostos altos & 1 & 0,1 & 2 & 0,3 \\
\hline Outros & 69 & 4,3 & 19 & 2,6 \\
\hline Total & 1620 & 100,0 & 724 & 100,0 \\
\hline
\end{tabular}

Fonte: Eseb 2002.

A avaliação da situação econômica do país foi aplicada apenas pelo Eseb 2014. Contudo, dada a relevância atribuída pela teoria da escolha racional ao voto econômico, ou ainda, à avaliação retrospectiva da economia e sua influência sobre o voto, consideramos a capacidade dessa variável de explicar o comportamento dos eleitores naquele pleito. Dessa forma, verificamos que, quando comparados aos eleitores brasileiros, os eleitores paulistas tenderam a considerar que a situação econômica do país permanecia igual nos últimos 12 meses. Dentre aqueles que se posicionaram nos extremos, a média dos brasileiros foi maior quando comparada à dos paulistas, seja para

\footnotetext{
${ }^{8}$ Para melhor visualização da distribuição das frequências, optamos pela apresentação dos dados sob o formato de tabela.
} 
os que disseram que a situação econômica do país melhorou ou para aqueles que apontaram que ela teria piorado (ver o Gráfico 12).

Gráfico 12

Avaliação da situação econômica do país nos últimos 12 meses

Brasil e São Paulo - 2014 (\%)

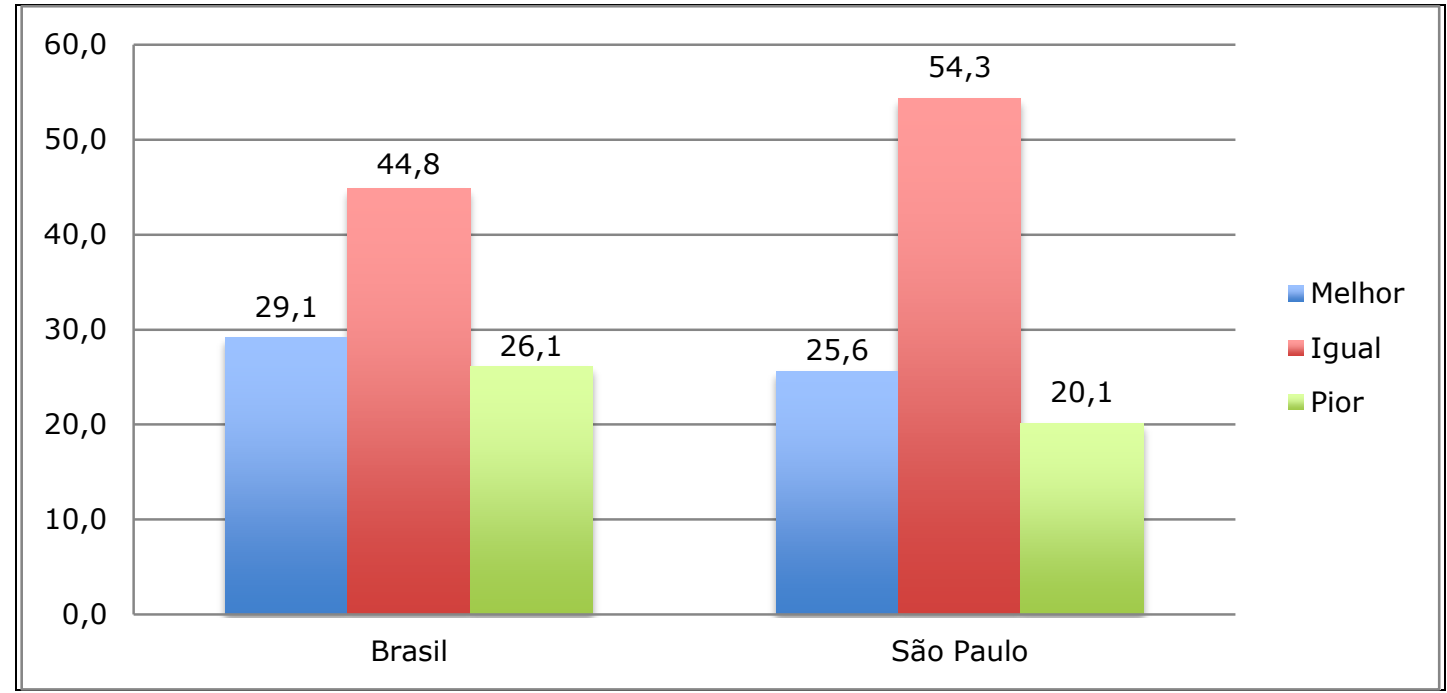

Fonte: Eseb 2014.

As variáveis sociodemográficas, identitárias e pragmáticas, descritas acima, serão utilizadas como preditoras para a análise do voto para presidente e governador de São Paulo no $1^{\circ}$ turno das eleições de 2002 e 2014, de que tratamos a seguir.

\section{Como se comportaram os eleitores paulistas e os eleitores brasileiros?}

O voto para presidente nas eleições de 2002 e 2014

A primeira variável dependente que analisamos foi o voto para presidente no 10 turno de 2002 (ver "Anexo metodológico"). Para essa variável, os testes de qui-quadrado e aqueles que resumem o modelo atestaram a relação das variáveis e os efeitos que dispuseram sobre o caso (ver a Tabela 3). Também recodificamos as respostas dessa variável em (0) voto em outros candidatos e (1) voto em Lula, em que consideramos as chances de alguém pertencente a cada um dos grupos analisados ter votado em Lula naquele pleito. Nesse sentido, foi possível observar que, no âmbito nacional, as categorias "renda familiar mensal acima de 20 salários mínimos", ser "evangélico", ser de "esquerda", "rejeitar o PT", "rejeitar o PSDB" e ter apontado a "inflação" como maior problema do Brasil explicaram, em diferentes sentidos, o comportamento eleitoral em 2002: em relação ao voto em Lula, aqueles com renda familiar mensal acima de 20 
salários mínimos mostraram as chances diminuídas em $74,2 \%$, quando comparados aos que possuíam renda familiar mensal inferior a um salário mínimo; ser evangélico mostrou $88,7 \%$ menos de chances, comparado a ser membro de outras religiões; os esquerdistas mostraram as chances aumentadas em $229,8 \%$, quando os comparamos aos centristas; a rejeição ao PT explicou o comportamento dos brasileiros em $-95,8 \%$ de chances; e, no sentido oposto, a rejeição ao PSDB apresentou $192,7 \%$ de chances ter votado em Lula, quando relacionados aos que não rejeitavam o partido tucano.

Entre os paulistas, as categorias que indicaram certa influência sobre o voto para presidente foram "ser evangélico", "ser de esquerda", "a rejeição ao PT", "a rejeição ao PSDB", além dos que "apontaram o desemprego" e "a fome, miséria e pobreza" como principais problemas do Brasil. Nesse caso, ainda quanto às chances de votar em Lula, "ser evangélico" representou -87,6\%; "ser de esquerda" teve 389,7\%; "rejeitar o PT" teve -97,7\%; "rejeitar o PSDB" impactou em 429,8\%; em relação aos principais problemas do país, aqueles que "apontaram o desemprego" tiveram $1.899,0 \%$, e os que "apontaram a fome, pobreza e miséria" tiveram $6.780,0 \%$ de chances de votar em Lula naquela ocasião (ver a Tabela 4).

Tabela 3

Testes de coeficientes de modelo Omnibus Voto para presidente no $1^{\circ}$ turno de 2002 - Brasil e São Paulo

\begin{tabular}{|c|c|c|c|c|c|c|c|c|c|}
\hline \multicolumn{5}{|l|}{ Brasil } & \multicolumn{5}{|c|}{ São Paulo } \\
\hline & & $\begin{array}{l}\text { Qui- } \\
\text { quadrado }\end{array}$ & df & Sig. & & & $\begin{array}{l}\text { Qui- } \\
\text { quadrado }\end{array}$ & df & Sig. \\
\hline \multirow{3}{*}{ Etapa 1} & Etapa & 209,078 & 43 & 0,000 & \multirow{3}{*}{$\begin{array}{l}\text { Etapa } \\
1\end{array}$} & Etapa & 152,06 & 41 & 0,000 \\
\hline & Bloco & 209,078 & 43 & 0,000 & & Bloco & 152,06 & 41 & 0,000 \\
\hline & Modelo & 209,078 & 43 & 0,000 & & Modelo & 152,06 & 41 & 0,000 \\
\hline \multicolumn{5}{|c|}{ Resumo do modelo } & \multicolumn{5}{|c|}{ Resumo do modelo } \\
\hline \multirow[t]{2}{*}{ Etapa 1} & \multicolumn{2}{|c|}{$\begin{array}{l}\text { Verossimilhança de } \\
\log -2\end{array}$} & $\begin{array}{l}\mathrm{R} \\
\text { quadrado } \\
\text { Cox \& } \\
\text { Snell }\end{array}$ & $\begin{array}{l}\mathrm{R} \\
\text { quadrado } \\
\text { Nagelkerke }\end{array}$ & \multirow[t]{2}{*}{$\begin{array}{l}\text { Etapa } \\
1\end{array}$} & \multicolumn{2}{|c|}{$\begin{array}{l}\text { Verossimilhança de } \\
\log -2\end{array}$} & $\begin{array}{l}\mathrm{R} \\
\text { quadrado } \\
\text { Cox \& } \\
\text { Snell }\end{array}$ & $\begin{array}{l}\text { R } \\
\text { quadrado } \\
\text { Nagelkerke }\end{array}$ \\
\hline & 496,630 & & 0,335 & 0,448 & & 147,526 & & 0,505 & 0,674 \\
\hline
\end{tabular}

Fonte: Eseb 2002. 
Tabela 4

Estatística de regressão logística binária: voto para presidente no 10 turno de 2002 - Brasil e São Paulo

\begin{tabular}{|l|l|c|c|c|c|c|c|c|}
\hline \multicolumn{1}{|l}{} & B & S.E. & Wald & df & Sig.* & $\begin{array}{c}\text { Exp } \\
\text { (B) }\end{array}$ & Chances \\
\hline \multirow{5}{*}{ Brasil } & $\begin{array}{l}\text { Faixa de renda familiar mensal: } \\
\text { Mais de 20 salários mínimos }\end{array}$ & $-1,355$ & 0,613 & 4,888 & 1 & 0,027 & 0,258 & $-74,2$ \\
\cline { 2 - 9 } & Religião: Evangélica & $-2,184$ & 0,429 & 25,866 & 1 & 0,000 & 0,113 & $-88,7$ \\
\cline { 2 - 9 } & $\begin{array}{l}\text { Autolocalização ideológica: } \\
\text { Esquerda }\end{array}$ & 1,193 & 0,332 & 12,955 & 1 & 0,000 & 3,298 & 229,8 \\
\cline { 2 - 9 } & Rejeição ao PT: Sim & $-3,163$ & 0,448 & 49,791 & 1 & 0,000 & 0,042 & $-95,8$ \\
\cline { 2 - 9 } & Rejeição ao PSDB: Sim & 1,074 & 0,256 & 17,623 & 1 & 0,000 & 2,927 & 192,7 \\
\hline \multirow{5}{*}{ São } \\
Paulo & Religião: Evangélica & $-2,088$ & 0,883 & 5,595 & 1 & 0,018 & 0,124 & $-87,6$ \\
\cline { 2 - 9 } & $\begin{array}{l}\text { Autolocalização ideológica: } \\
\text { Esquerda }\end{array}$ & 1,589 & 0,701 & 5,14 & 1 & 0,023 & 4,897 & 389,7 \\
\cline { 2 - 9 } & Rejeição ao PT: Sim & $-3,777$ & 0,813 & 21,568 & 1 & 0,000 & 0,023 & $-97,7$ \\
\cline { 2 - 9 } & Rejeição ao PSDB: Sim & 1,667 & 0,569 & 8,579 & 1 & 0,003 & 5,298 & 429,8 \\
\cline { 2 - 8 } & $\begin{array}{l}\text { Maior problema do Brasil: } \\
\text { Desemprego }\end{array}$ & 2,995 & 1,443 & 4,306 & 1 & 0,038 & 19,989 & 1899,0 \\
\cline { 2 - 8 } & $\begin{array}{l}\text { Maior problema do Brasil: Fome/ } \\
\text { Pobreza/Miséria }\end{array}$ & 4,231 & 1,809 & 5,472 & 1 & 0,019 & 68,803 & 6780,0 \\
\hline
\end{tabular}

\section{Fonte: Eseb 2002.}

Variável dependente: Voto para presidente no $1^{\circ}$ turno de 2002: (0) Outros candidatos; (1) Lula.

(*) Significativo a 0,05.

Os dados acima nos permitem afirmar que, em 2002, as variáveis religião (evangélica), autolocalização ideológica (esquerda) e rejeição partidária (ao PT e ao PSDB) exerceram comum efeito sobre o comportamento dos eleitores paulistas e brasileiros. No entanto, a intensidade de todas essas variáveis foi maior entre os paulistas. Além destas, o apontamento do desemprego e da fome/pobreza/miséria como principais problemas do país também exerceram influência sobre o voto dos eleitores paulistas e não apresentaram relações significativas com o voto dos eleitores brasileiros. A variável renda familiar mensal, de caráter sociodemográfico, surtiu efeito apenas entre os eleitores dos outros estados brasileiros, sem o mesmo desempenho em São Paulo. Podemos, então, considerar que, na escolha de seu candidato a presidente em 2002, os paulistas tenderam a levar em conta, em maior quantidade e intensidade, as razões de ordem pragmática, comparados aos brasileiros dos outros estados.

Acerca das eleições de 2014, os testes de qui-quadrado, verossimilhança log - 2 e $\mathrm{R}^{2}$ Cox \& Snell e $\mathrm{R}^{2}$ Nagelkerke indicam não apenas a relação das variáveis do modelo mas também que suas medidas de qualidade de ajuste podem ser consideradas aceitáveis (ver Tabela 5). Adiante, os testes de regressão logística revelaram que, na 
média dos estados brasileiros, as variáveis rejeição ao PT, avaliação do governo Dilma, opinião sobre a situação econômica e satisfação com a democracia exerceram influência sobre o voto para presidente naquele ano. Verificamos, assim, em relação às chances de votar em Dilma, que alguém que manifestou rejeição ao PT teve as chances diminuídas em $51,7 \%$; aqueles que manifestaram rejeição ao PSDB tiveram as chances aumentadas em 95\%; os que avaliaram seu governo como ótimo e bom tiveram $3.637,0 \%$ e $1.768,0 \%$, respectivamente; também aqueles que avaliaram a situação econômica como melhor ou igual ultrapassaram os $104 \%$; os percentuais de chances também foram elevados entre os que manifestaram ao menos um pouco de satisfação com a democracia - entre os indiferentes, as chances 202,5\%; já as demais categorias apresentaram índices ainda maiores (ver a Tabela 6).

No caso de São Paulo, das variáveis que compuseram nosso modelo, a única que apresentou potencial preditivo sobre o voto em Dilma em 2014 foi a rejeição partidária ao PT. Naquela ocasião, as chances de alguém que rejeitava o PT ter votado em Dilma foi de $-78,5 \%$ quando comparamos àqueles que votaram em outros candidatos. Nem as variáveis de caráter sociodemográfico e identitário, ou mesmo as relacionadas à avaliação do governo e da economia e à satisfação em relação à democracia, foram suficientemente capazes de explicar o voto dos paulistas para presidente em 2014.

Tabela 5

Testes de coeficientes de modelo Omnibus

Voto para presidente no $1^{\circ}$ turno de 2014 - Brasil e São Paulo

\begin{tabular}{|c|c|c|c|c|c|c|c|c|c|}
\hline \multicolumn{5}{|c|}{ Brasil } & \multicolumn{5}{|c|}{ São Paulo } \\
\hline & & $\begin{array}{l}\text { Qui- } \\
\text { quadrado }\end{array}$ & df & Sig. & & & $\begin{array}{l}\text { Qui- } \\
\text { quadrado }\end{array}$ & df & Sig. \\
\hline \multirow{3}{*}{$\begin{array}{l}\text { Etapa } \\
1\end{array}$} & Etapa & 328,344 & 37 & 0,000 & \multirow{3}{*}{$\begin{array}{l}\text { Etapa } \\
1\end{array}$} & Etapa & 126,86 & 36 & 0,000 \\
\hline & Bloco & 328,344 & 37 & 0,000 & & Bloco & 126,86 & 36 & 0,000 \\
\hline & Modelo & 328,344 & 37 & 0,000 & & Modelo & 126,86 & 36 & 0,000 \\
\hline
\end{tabular}

\begin{tabular}{|c|c|c|c|c|c|c|c|}
\hline \multicolumn{4}{|c|}{ Resumo do modelo } & \multicolumn{4}{|c|}{ Resumo do modelo } \\
\hline \multirow[t]{2}{*}{$\begin{array}{l}\text { Etapa } \\
1\end{array}$} & $\begin{array}{l}\text { Verossimilhança de } \\
\log -2\end{array}$ & $\begin{array}{l}\text { R } \\
\text { quadrado } \\
\text { Cox \& } \\
\text { Snell }\end{array}$ & $\begin{array}{l}\text { R } \\
\text { quadrado } \\
\text { Nagelkerke }\end{array}$ & \multirow[t]{2}{*}{$\begin{array}{l}\text { Etapa } \\
1\end{array}$} & $\begin{array}{l}\text { Verossimilhança de } \\
\log -2\end{array}$ & $\begin{array}{l}\text { R } \\
\text { quadrado } \\
\text { Cox \& } \\
\text { Snell }\end{array}$ & $\begin{array}{l}\mathrm{R} \\
\text { quadrado } \\
\text { Nagelkerke }\end{array}$ \\
\hline & 485,858 & 0,427 & 0,571 & & 102,343 & 0,53 & 0,712 \\
\hline
\end{tabular}

Fonte: Eseb 2014. 
Tabela 6

Estatística de regressão logística binária: voto para presidente no 10 turno de 2014 - Brasil e São Paulo

\begin{tabular}{|c|c|c|c|c|c|c|c|c|}
\hline & & B & S.E. & Wald & df & Sig. & $\begin{array}{l}\text { Exp } \\
\text { (B) }\end{array}$ & Chances \\
\hline \multirow{10}{*}{ Brasil } & Rejeição ao PT: Rejeita & $-0,727$ & 0,328 & 4,923 & 1 & 0,026 & 0,483 & $-51,7$ \\
\hline & Rejeição ao PSDB: Rejeita & 0,668 & 0,293 & 5,191 & 1 & 0,023 & 1,95 & 95,0 \\
\hline & Avaliação do governo Dilma: Ótimo & 3,621 & 1,176 & 9,477 & 1 & 0,002 & 37,372 & 3637,0 \\
\hline & Avaliação do governo Dilma: Bom & 2,927 & 1,09 & 7,217 & 1 & 0,007 & 18,679 & 1768,0 \\
\hline & Opinião da situação econômica: Melhor & 0,766 & 0,332 & 5,322 & 1 & 0,021 & 2,15 & 115,0 \\
\hline & Opinião da situação econômica: Igual & 0,715 & 0,301 & 5,649 & 1 & 0,017 & 2,045 & 104,5 \\
\hline & $\begin{array}{l}\text { Satisfação com a democracia: Muito } \\
\text { satisfeito }\end{array}$ & 1,411 & 0,613 & 5,297 & 1 & 0,021 & 4,099 & 309,9 \\
\hline & Satisfação com a democracia: Satisfeito & 1,551 & 0,437 & 12,571 & 1 & 0,000 & 4,714 & 371,4 \\
\hline & Satisfação com a democracia: Indiferente & 1,107 & 0,465 & 5,671 & 1 & 0,017 & 3,025 & 202,5 \\
\hline & $\begin{array}{l}\text { Satisfação com a democracia: Pouco } \\
\text { satisfeito }\end{array}$ & 1,256 & 0,449 & 7,841 & 1 & 0,005 & 3,511 & 251,1 \\
\hline $\begin{array}{l}\text { São } \\
\text { Paulo }\end{array}$ & Rejeição ao PT: Rejeita & $-1,538$ & 0,784 & 3,854 & 1 & 0,050 & 0,215 & $-78,5$ \\
\hline
\end{tabular}

Fonte: Eseb 2014.

Variável dependente: Voto para presidente no 10 turno de 2014: (0) Outros candidatos; (1) Dilma.

(*) Significativo a 0,05.

O fenômeno da rejeição do PT, ou antipetismo, também é observado nos artigos de Braga e Casalecchi (2016), Paiva, Krause e Lameirão (2016), Ribeiro, Carreirão e Borba (2016) e Speck e Balbachevsky (2016), na edição da revista Opinião Pública, com artigos baseados no Eseb 2014 (vol. 22, no 3 - dez. 2016). No geral, esses autores destacaram o perfil social, os valores e os sentimentos políticos do eleitor antipetista. Braga e Casalecchi (2016, p. 559), ao analisarem o comportamento de vencedores e perdedores nas eleições de 2014, relacionaram a rejeição partidária e a adesão à democracia e afirmaram que "quem vive [no estado de São Paulo] tem menos chances de aderir à democracia do que quem vive em outro estado, isto é: os paulistas são mais autoritários". Além disso, "os perdedores que vivem em São Paulo têm uma probabilidade menor de aderir à democracia. Isso significa que, além do efeito direto, viver em São Paulo tem também um efeito indireto sobre a não adesão à democracia" (Braga e Casalecchi, 2016, p. 561-562).

Paiva, Krause e Lameirão (2016, p. 651), embora não se direcionem diretamente aos paulistas, afirmaram que a maioria dos antipetistas, quando comparados aos antipartidários em geral, se caracteriza como branco, com o ensino médio ou superior completos e renda elevada. Em sua análise, as autoras também destacaram a predisposição ideológica dos antipetistas ao PSDB. 
Num sentido semelhante, Ribeiro, Carreirão e Borba (2016, p. 622-623) verificaram que os antipetistas tendem a ser brancos, mais velhos e menos igualitaristas $^{9}$. Dentre outros aspectos, esses autores também ressaltam o maior peso que a rejeição tem obtido em relação à adesão a algum partido.

Speck e Balbachevsky (2016, p. 587) observaram que "a identificação partidária tem consequências diferentes não somente entre eleitores de diferentes partidos, mas também entre diferentes segmentos da sociedade". Para eles, os petistas menos favorecidos são mais fiéis ao seu partido na hora de votar para presidente do que os partidários do PSDB. O contrário ocorre com os peessedebistas, uma vez que os mais favorecidos tendem a ser mais coerentes e fiéis ao partido. Portanto, a condição socioeconômica apresenta um impacto significativo sobre o comportamento de petistas e peessedebistas.

Além de especificarem o antipetismo, as considerações dos autores citados corroboram a tendência de um comportamento pragmático, presente no eleitorado brasileiro, mas com maior intensidade sobre o eleitorado paulista, como observamos nos dados apresentados acima.

O voto para governador de São Paulo nas eleições de 2002 e 2014

Nosso interesse ao analisar o voto para governador foi verificar se as variáveis que explicam o voto do eleitor para presidente são os mesmos que atuam na escolha para governador de São Paulo. Nesse sentido, para as eleições de 2002, os testes estatísticos indicaram a existência de relação entre as variáveis estudadas e a aceitação dos efeitos sobre a variável resposta (ver a Tabela 7). Dessa maneira, notamos que a rejeição partidária e o apontamento dos maiores problemas do Brasil foram as principais variáveis do modelo empregado que impactaram sobre o voto em Alckmin nas eleições de 2002: rejeitar o PT também impactou em 191,9\% na escolha de Alckmin para governador; e ter apontado o desemprego, a corrupção, a fome/pobreza/miséria e a dívida externa como maiores problemas do país reduziram as chances de voto em Alckmin em -94,5\%, -97,5\%, -99,0\% e -98,4\%, respectivamente.

Outro ponto que nos chamou a atenção foi que as variáveis rejeição partidária ao PT, desemprego e fome/pobreza/miséria foram significativas para a explicação tanto do voto dos eleitores paulistas para presidente como também para governador do estado.

Ainda, as variáveis de caráter sociodemográfico (renda, escolaridade, gênero, faixa etária e religião) e identitário (autolocalização ideológica e interesse por política) não foram suficientes para explicar o voto em Alckmin em 2002, havendo um predomínio das razões pragmáticas. Em específico, é preciso ressaltar que nas ondas do Eseb não há

\footnotetext{
${ }^{9}$ Sobre a variável igualitarismo, os autores utilizaram duas questões do Eseb 2014: 1) "Em qualquer situação as pessoas mais pobres devem ter mais chances do que as mais ricas"; e 2) "As cotas reservadas para negros e índios prejudicam quem tem mais competência". Para ambas, as respostas foram dadas sob o formato de escala de concordância com cinco pontos.
} 
questões relacionadas à avaliação retrospectiva dos governos estaduais, o que nos impede de analisar o impacto dessa variável sobre o voto para candidatos a governador. De qualquer maneira, utilizamos a avaliação do governo federal como uma tentativa de verificar se houve algum efeito desta sobre o voto na esfera estadual, o que não ocorreu.

Tabela 7

Testes de coeficientes de modelo Omnibus

Voto para governador de São Paulo - $1^{\circ}$ turno de 2002

\begin{tabular}{|l|l|l|l|l|}
\hline \multirow{2}{*}{} & \multicolumn{2}{|l|}{$\begin{array}{l}\text { Qui- } \\
\text { quadrado }\end{array}$} & df & Sig. \\
\hline \multirow{3}{*}{ Etapa 1} & Etapa & 86,266 & 41 & 0,000 \\
\cline { 2 - 5 } & Bloco & 86,266 & 41 & 0,000 \\
\cline { 2 - 5 } & Modelo & 86,266 & 41 & 0,000 \\
\hline \multirow{2}{*}{ Resumo do modelo } & R quadrado Cox \& Snell & R quadrado Nagelkerke \\
\hline \multirow{2}{*}{ Etapa 1} & Verossimilhança de log -2 & 0,347 & 0,463 \\
\cline { 2 - 5 } & 194,025 &
\end{tabular}

Fonte: Eseb 2002.

Tabela 8

Estatística de regressão logística binária Voto para governador de São Paulo no $1^{\circ}$ turno de 2002

\begin{tabular}{|c|c|c|c|c|c|c|c|c|}
\hline & & B & S.E. & Wald & df & Sig. & $\begin{array}{l}\text { Exp } \\
\text { (B) }\end{array}$ & Chances \\
\hline & Rejeição ao PT: Sim & 1,071 & 0,521 & 4,236 & 1 & 0,040 & 2,919 & 191,9 \\
\hline & $\begin{array}{l}\text { Maior problema do Brasil: } \\
\text { Desemprego }\end{array}$ & $-2,906$ & 1,375 & 4,468 & 1 & 0,035 & 0,055 & $-94,5$ \\
\hline São & $\begin{array}{l}\text { Maior problema do Brasil: } \\
\text { Corrupção }\end{array}$ & $-3,686$ & 1,77 & 4,336 & 1 & 0,037 & 0,025 & $-97,5$ \\
\hline Padur & $\begin{array}{l}\text { Maior problema do Brasil: } \\
\text { Fome / Pobreza / Miséria }\end{array}$ & $-4,572$ & 1,66 & 7,585 & 1 & 0,006 & 0,010 & $-99,0$ \\
\hline & $\begin{array}{l}\text { Maior problema do Brasil: } \\
\text { Dívida externa }\end{array}$ & $-4,132$ & 2,092 & 3,899 & 1 & 0,048 & 0,016 & $-98,4$ \\
\hline
\end{tabular}

Fonte: Eseb 2002.

Variável dependente: Voto para governador no $1^{\circ}$ turno de 2002: (0) Outros candidatos; (1) Alckmin.

(*) Significativo a 0,05 .

Sobre o voto para governador de São Paulo no 10 turno de 2014, os testes de qui-quadrado, verossimilhança log $-2, R^{2}$ Cox \& Snell e $R^{2}$ Nagelkerke também atestaram a relação entre as variáveis e o efeito das previsoras do modelo sobre as respostas. Naquele ano, a rejeição partidária foi a única variável do nosso modelo capaz de predizer o voto em Alckmin. A rejeição ao PSDB apresentou $-71,7 \%$ de chances de ter votado em Alckmin, enquanto a rejeição ao PT indicou um percentual positivo e muito elevado de 
chances, $739,7 \%$, de ter votado em Alckmin e contribuiu para a sexta eleição vitoriosa consecutiva do PSDB ao comando do poder Executivo estadual.

Tabela 9

Testes de coeficientes de modelo Omnbus

Voto para governador de São Paulo - $1^{\circ}$ turno de 2014

\begin{tabular}{|l|c|c|c|c|}
\hline \multirow{4}{*}{ Etapa 1 } & & Qui-quadrado & df & Sig. \\
\cline { 2 - 5 } & Etapa & 66,150 & 32 & 0,000 \\
\cline { 2 - 5 } & Bloco & 66,150 & 32 & 0,000 \\
\cline { 2 - 5 } & Modelo & 66,150 & 32 & 0,000 \\
\hline \multirow{2}{*}{ Resumo do modelo } & $\begin{array}{c}\text { R quadrado Cox \& } \\
\text { Snell }\end{array}$ & R quadrado Nagelkerke \\
\hline \multirow{2}{*}{ Etapa 1 } & \multicolumn{2}{|c|}{ Verossimilhança de log -2 } & 0,391 & 0,542 \\
\cline { 2 - 5 } & \multicolumn{2}{|c|}{104,395} & &
\end{tabular}

Fonte: Eseb 2014.

Tabela 10

Estatística de regressão logística binária Voto para governador no $1^{\circ}$ turno de 2014 - São Paulo

\begin{tabular}{|l|l|l|l|l|l|l|l|l|}
\hline \multicolumn{2}{|c}{} & B & S.E. & Wald & df & Sig. & Exp(B) & Chances \\
\hline \multirow{3}{*}{ São Paulo } & Rejeição ao PT: Sim & 2,128 & 0,925 & 5,287 & 1 & 0,021 & 8,397 & 739,7 \\
\cline { 2 - 9 } & Rejeição ao PSDB: Sim & $-1,262$ & 0,576 & 4,798 & 1 & 0,028 & 0,283 & $-71,7$ \\
\hline
\end{tabular}

Fonte: Eseb 2014.

Variável dependente: Voto para governador no $1^{\circ}$ turno de 2014: (0) Outros candidatos; (1) Alckmin.

(*) Significativo a 0,05.

Comparada às eleições presidenciais, a rejeição partidária ao PT se repetiu como variável explicativa para o voto ao governo de São Paulo. Nesse caso, a rejeição ao PSDB também teve impacto (negativo) sobre o voto em Alckmin. Essa constatação nos permite afirmar, portanto, que o eleitorado paulista tende a atribuir razões prioritariamente pragmáticas para o seu voto para presidente e para governador, porém com mais intensidade que o eleitorado brasileiro. Isso porque as variáveis pragmáticas são explicativas no âmbito nacional, mas a força de seus efeitos sobre o eleitorado paulista é relativamente maior.

\section{Conclusões}

De 2002 para 2014, o eleitorado paulista se caracterizou por apresentar maior renda familiar mensal, maiores níveis de escolaridade, uma população mais envelhecida, uma divisão equivalente entre mulheres e homens e uma redução mais acentuada do 
número de católicos e ascensão de outras religiões, sobretudo de evangélicos, quando comparado ao eleitorado brasileiro.

Ideologicamente, paulistas e brasileiros de outros estados tenderam à redução da esquerda e ao aumento do centro e da direita. E, em relação ao interesse por política, os paulistas demonstraram menor interesse que a média dos brasileiros.

Dentre as características relativas às avaliações sobre democracia, governo e economia, e ao recebimento do Programa Bolsa Família, os paulistas passaram de insatisfeitos para satisfeitos com o funcionamento da democracia, quando comparados à média dos estados brasileiros; mantiveram níveis semelhantes aos dos brasileiros no que se refere à adesão à democracia; avaliaram a situação econômica do país entre igual ou melhor em 2014; e foram mais críticos aos governos de Fernando Henrique Cardoso e de Dilma. Entre os paulistas também encontramos um menor percentual de beneficiados do Programa Bolsa Família - aproximadamente 15\% a menos que a média da amostra nacional.

A rejeição partidária ao PT já era superior entre os paulistas em 2002 e tornou-se ainda maior em 2014, quando comparada à dos eleitores brasileiros. O contrário ocorreu em relação ao PSDB, cuja rejeição foi maior entre os eleitores dos outros estados que entre os eleitores paulistas.

No que diz respeito ao comportamento dos eleitores paulistas e brasileiros, os testes estatísticos nos permitiram confirmar parcialmente nossa principal hipótese. Isso porque os dados apresentados ressaltam o que Albuquerque (1992) já havia apontado acerca das razões de ordem pragmática, que teriam passado a ser comuns e a dispor de maior capacidade preditiva nas disputas eleitorais nacionais. No entanto, outras variáveis sociodemográficas e identitárias também demonstram atuar sobre o comportamento eleitoral dos brasileiros. Por outro lado, ao compararmos o eleitorado nacional com o paulista, verificamos que este tende a considerar muito mais as razões de ordem pragmática - sobretudo pela intensidade das variáveis - do que os aspectos sociodemográficos e identitários.

No caso do $1^{0}$ turno da disputa presidencial de 2002, verificamos que a renda familiar mensal (acima de 20 salários mínimos) e a religião (evangélica) demonstraramse significativas no plano nacional, mas, em São Paulo, apenas a religião (evangélica) atuou da mesma forma. A classificação ideológica de esquerda foi significativa nas duas esferas, mas com maior intensidade entre os paulistas. Especial atenção deve ser dada às fortes correlações e às elevadas chances das variáveis de rejeição partidária e das que apontam para os maiores problemas do Brasil. Em particular, essas variáveis pareceram exercer ainda maior influência em São Paulo do que nos outros estados brasileiros.

$\mathrm{Na}$ eleição para presidente de 2014, em nível nacional, das variáveis e categorias elencadas, 11 apresentaram índices significativos para explicar o voto em Dilma. Nenhuma delas corresponde à categoria de variáveis sociodemográficas e de identificação ideológica. Todas pertencem ao grupo de variáveis pragmáticas: a rejeição 
ao PT, a rejeição ao PSDB, a avaliação do governo Dilma, a avaliação sobre a situação econômica e a satisfação com o funcionamento da democracia. Em comparação com os resultados obtidos em 2002, podemos afirmar que as razões pragmáticas exerceram um domínio sobre as razões que definiram o voto dos brasileiros em 2014.

Entretanto, se no plano nacional 11 variáveis demonstraram forte capacidade preditora, no estado de São Paulo apenas uma variável atuou da mesma maneira: a rejeição ao PT. As urnas confirmaram que Dilma não obteve a maioria dos votos em São Paulo. Mas chama atenção a ausência de outras variáveis no modelo elaborado que também pudessem explicar esse comportamento do eleitorado paulista, apesar de os testes estatísticos terem confirmado a relação entre as variáveis e os ajustes do modelo e seu poder preditivo ter correspondido a $71,2 \%$.

O cenário pouco se difere nas disputas pelo Executivo estadual. Em 2002, apenas as variáveis pragmáticas (rejeição ao PT e problemas do país: desemprego, corrupção, dívida externa e fome/pobreza/miséria) explicaram o comportamento dos paulistas na escolha para governador do estado. Cabe ressaltar que três dessas variáveis também foram explicativas para o voto do eleitorado paulista para presidente (rejeição ao PT, desemprego e fome/pobreza/miséria), o que nos dá margem para considerar que os paulistas tendem a recorrer a critérios semelhantes para a escolha de seus candidatos nas esferas do Executivo federal e estadual.

Em 2014, apenas a rejeição partidária, ao PT e ao PSDB, demonstrou capacidade preditiva significativa sobre a escolha dos paulistas para o governo do estado. No entanto, se consideramos o voto para presidente - que também sofreu influência da rejeição ao PT -, o antipetismo foi muito mais elevado e a rejeição ao PSDB foi proporcionalmente menor no âmbito estadual.

Em síntese, vimos que o eleitorado paulista tende a atribuir razões prioritariamente pragmáticas para o seu voto tanto para presidente quanto para governador. Apesar de as variáveis pragmáticas também serem capazes de explicar o comportamento do eleitorado nacional, a atuação e o efeito destas sobre o eleitorado paulista é consideravelmente superior. Um exemplo disso é que a rejeição ao PT foi tão significativa em São Paulo que parece ter minimizado o efeito de outras variáveis. $O$ antipetismo, embora seja um fenômeno nacional, apresenta-se mais intenso em São Paulo, estado originário do PT.

Quando comparados ao início das pesquisas de comportamento eleitoral em São Paulo, sobretudo entre os paulistanos, os dados nos revelaram que há uma modificação do conjunto de variáveis que influenciam as decisões políticas do eleitorado paulista. Estudos anteriores apontavam para as variáveis urbano-rural, classe social, preferência partidária, relações com líderes, entre outras. Neste artigo, foi possível demonstrar que, de 2002 para 2014, as variáveis pragmáticas passaram a exercer maior efeito sobre o comportamento dos eleitores paulistas, principalmente a rejeição partidária. 
No plano nacional, as razões pragmáticas também demonstraram exercer influência sobre o voto, porém com menor intensidade em relação ao estado de São Paulo. Além disso, um número maior de variáveis dessa categoria tendeu a explicar o comportamento dos eleitores brasileiros em 2002 e 2014.

Certamente, novos estudos sobre o comportamento eleitoral dos paulistas serão desenvolvidos e essas e outras variáveis deverão ser testadas. Esperamos que este artigo possa, de alguma forma, contribuir para o questionamento, a discussão e a compreensão do comportamento de paulistas e brasileiros.

Maria Teresa Miceli Kerbauy - Programa de Pós-Graduação em Ciências Sociais, Faculdade de Ciências e Letras, Universidade Estadual Paulista. Bolsista de produtividade do CNPq. E-mail: <kerbauy@travelnet.com.br>.

André Luiz Vieira Dias - Doutorando no Programa de Pós-Graduação em Ciências Sociais, Faculdade de Ciências e Letras, Universidade Estadual Paulista. Bolsista Capes.

E-mail: <andrelvdias@me.com>.

\section{Referências bibliográficas}

Albuquerque, J. A. G. "Identidade, oposição e pragmatismo: uma teoria política do voto". Lua Nova, São Paulo, nº 26, p. 53-79, 1992.

ALFORD, R. R. Class voting in the Anglo American political systems. In: LIPSET, S.; ROKKAN, S. (orgs.). Party systems and voter alignment: cross-national perspectives. New York: The Free Press, 1967.

AlmeidA, A. C. A cabeça do brasileiro. São Paulo: Record, 2007.

ALmOND, G.; Verba, S. The civic culture. Princeton: Princeton University Press, 1963.

BALBACHEVSKY, E.; HOLZHACKER, D. "Identidade, oposição e pragmatismo: o conteúdo estratégico da decisão eleitoral em 13 anos de eleições". Opinião Pública, Campinas, vol. 10, n² 2, p. 243-253, out. 2004.

BerInSkY, A.; LeNZ, G. "Education and political participation: exploring the causal link". Political Behavior, vol. 33, p. 357-373, 2011.

BRAGA, M. S. S.; CASAlECCHI, G. A. "Vencedores e perdedores nas eleições presidenciais de 2014". Opinião Pública, Campinas, vol. 22, n³, p. 550-568, 2016.

CAmpbelL, A., et al. The American voter. New York: John Wiley and Sons Inc., 1964.

CARREIRÃo, Y.S. A decisão do voto nas eleições presidenciais brasileiras. Florianópolis: Editora da UFSC; Rio de Janeiro: FGV, 2002.

CASTRO, M. M. M. "Determinantes do comportamento eleitoral: a centralidade da sofisticação política". Tese de Doutorado em Ciência Política. Iuperj, Rio de Janeiro, 1994.

Cesop. Opinião Pública, Tendências: Eseb-CSES 2010, Campinas, vol. 17, n² 2, p. 516-540, nov. 2011.

Coleman, J. S. Foundations of social theory. Cambridge: Belknap, 1990.

CONVERSE, P. The nature of belief systems in mass publics. In: APTER, D. (org.). Ideology and discontent. New York: Free Pass, p. 206-261, 1964. 
DALTON, R. J. The good citizen: how younger generation is reshaping American politics. Washington: CQ Press, 2009.

. Citizen politics: public opinion and political parties in advanced industrial. Los Angeles: Sage Publications, 2014.

DALTON, R. J.; KLingemanN, H. The Oxford handbook of political behavior. New York: Oxford University Press, 2007.

DiAs, A. L. V.; KerbauY, M. T. M. "Engajamento cívico e escolaridade superior: as eleições de 2014 e o comportamento político dos brasileiros". Revista de Sociologia e Política, Curitiba, vol. 23, n 56, p. 149-181, dez. 2015.

Downs, A. An economic theory of democracy. New York: Harper \& Row Publishers, 1957.

Ferreira, O. S. "Comportamento eleitoral em São Paulo". Revista Brasileira de Estudos Políticos, Belo Horizonte, n० 8, 1960. $16,1964$.

. "As eleições paulistas de 1962". Revista Brasileira de Estudos Políticos, Belo Horizonte, no

Figueiredo, M. A decisão do voto: democracia e racionalidade. São Paulo: Sumaré, 1991.

Figueiredo, A., et al. "Partidos e distribuição espacial do voto na cidade de São Paulo". Novos Estudos Cebrap, São Paulo, no 64, p. 153-160, 2002.

FIORINA, M. P. Retrospecting voting in American national elections. New Haven: Yale University Press, 1981.

HOLZHACKER, D.; BALBACHEVSKY, E. "Classe, ideologia e política: uma interpretação dos resultados das eleições de 2002 e 2006". Opinião Pública, Campinas, vol. 13, n² 2, p. 283-306, nov. 2007.

KAM, C. D.; PALMER, C. L. "Reconsidering the effects of education on political participation". The Journal of Politics, vol. 70, n 3, p. 612-631, 2008.

KEY, V. O. The responsible electorate: rationality in presidential voting (1936-1966). Cambridge: Belknap Press, 1966.

Kinzo, M. D. A eleição presidencial de 1994 no Brasil: Fernando Henrique Cardoso e o Plano Real. In: Pinto, C.; Guerreiro, H. América Latina: o desafio da democracia nos anos 90. Porto Alegre: UFRGS, 1996.

Kuklinsky, J. H.; Peyton, B. Beliefs systems and political decision making. In: Dalton, R. J.; KLINGEMANN, H. The Oxford handbook of political behavior. New York: Oxford University Press, p. 4564, 2007.

LAMOUnier, B. Comportamento eleitoral em São Paulo: passado e presente. In: CARdoso, F. H.; LAmounier, B. Os partidos e as eleições no Brasil. São Paulo: Paz e Terra/Cebrap, p. 15-44, 1975.

. O voto em São Paulo (1970-1978). In: LAMOunier, B. (org.). Voto de desconfiança. Rio de Janeiro: Vozes, 1980.

LAMOUNIER, B. (org.). 1985: o voto em São Paulo. São Paulo: Idesp, 1986.

LAmounier, B.; Muszinski, J. "São Paulo, 1982: a vitória do (P)MDB". In: Anais do 70 Encontro Anual da Anpocs. Águas de São Pedro, out. 1983.

Lavareda, A. A democracia nas urnas. Rio de Janeiro: Iuperj/Rio Fundo, 1991.

LazARsfeld, P. F.; Berelson, B.; Gaudet, H. The people's choice: how the voter makes up his mind in a presidential campaign. New York: Columbia University Press, 1944.

LEWIS-BECK, M. Economics \& elections: major western democracies. Ann Arbor: The University of Michigan Press, 1988.

LEWIS-BECK, M. S., et al. The American voter revisited. Ann Arbor: The University of Michigan Press, 2008. 
Limongi, F.; CORTEZ, R. "As eleições de 2010 e o quadro partidário". Novos Estudos Cebrap, São Paulo, no 88, p. 21-37, nov. 2010.

LIMONGI, F.; MEsquitA, F. "As eleições municipais em São Paulo entre 1985 e 2004". Novos Estudos Cebrap, São Paulo, no 81, p. 49-67, jul. 2008.

LIPSET. S. M. O homem político. Rio de Janeiro: Zahar, 1967.

MilleR, W.; SHANKS, J. M. The new American voter. Cambridge, MA: Harvard University Press, 1996.

MUSZYNSKI, J. O eleitorado paulistano em 1986: a marca do oposicionismo. Idesp, São Paulo, 1988.

NiE, N. H.; ANDERSEn, K. "Mass beliefs systems revisited: political change and attitude structure". The Journal of Politics, vol. 36, 1974.

NIE, N. H., et al. The changing American voter. Cambridge: Harvard University Press, 1976.

NiE, N. H.; Hillygus, D. S. Education and democratic citizenship: explorations into the effects of what happens in pursuit of the baccalaureate. In: RAVITCH, D.; VITERITTI, J. (orgs.). Education and civil society. New Haven, CT: Yale University Press, 2001.

NORRIS, P. Critical citizens: global support for democratic governance. Oxford: Oxford University Press. 1998.

OliveirA, C.; TURGEON, M. "Ideologia e comportamento político no eleitorado brasileiro". Opinião Pública, Campinas, vol. 21, no 3, p. 574-600, dez. 2015.

PAiva, D.; KRAUSE, S.; LAMEIRÃO, A. P. "O eleitor antipetista: partidarismo e avaliação restrospectiva". Opinião Pública, Campinas, vol. 22, n³ 3, p. 638-674, 2016.

Pierucci, F. "A direita mora do outro lado da cidade". Revista Brasileira de Ciências Sociais, São Paulo, no 10, p. 44-64, 1989.

PieruCCI, F.; LIMA, M. C. "A direita que flutua: o voto conservador nas eleições de 1990 em São Paulo". Novos Estudos Cebrap, São Paulo, no 29, p. 10-21, 1991.

PierucCI, F.; LimA, M. C. "São Paulo 92: a vitória da direita". Novos Estudos Cebrap, São Paulo, no 35, p. 94-99, 1993.

POPKIN, S., et al. "Comment: what have you done for me lately? Toward an investment theory of voting". The American Political Science Review, vol. 70, n³ 3, 1976.

REIS, F. W. Regiões, classe e ideologia no processo eleitoral brasileiro. In: REIS, F. W. Mercado e utopia. São Paulo, Edusp, p. 281-325, 2000.

RENNó, L.; AMES, B. "PT no purgatório: ambivalência eleitoral no primeiro turno das eleições presidenciais de 2010". Opinião Pública, Campinas, vol. 20, nº 1, p. 1-25, abr. 2014.

RenNó, L.; CABELLo, A. "As bases do lulismo: a volta do personalismo, realinhamento ideológico ou não alinhamento". Revista Brasileira de Ciências Sociais, São Paulo, vol. 25, no 74, p. 39-60, out. 2010.

Ribeiro, E.; CARReirÃo, Y.; Borba, J. "Sentimentos partidários e antipetismo: condicionantes e covariantes". Opinião Pública, Campinas, vol. 22, n 3, p. 603-637, 2016.

RIKER, W. H. Liberalism against populism. San Francisco: W. Freeman and Company, 1983.

SCHLEGEL, R. "Educação e comportamento político: os retornos políticos decrescentes da escolarização brasileira recente". Tese de Doutorado. Faculdade de Filosofia, Letras e Ciências Humanas da Universidade de São Paulo, 2010.

SCHLEGEL, R. A educação brasileira e seus retornos políticos decrescentes. In: MoISÉs, J. A.; Meneguello, R. (orgs.). A desconfiança política e os seus impactos na qualidade da democracia. São Paulo: Edusp, 2013. 
SCHLOZMAN, K. L. Citizen participation in America: what do we know? Why do we care? In: Katznelson, I.; Milner, H. V. (orgs.). Political science: state of the discipline. New York: W. W. Norton \& Company, 2002.

SchwartZman, S. São Paulo e o Estado nacional. São Paulo: Difel, 1975.

. Bases do autoritarismo brasileiro. Rio de Janeiro: Campus, 1982.

Silveira, F. E. "O novo eleitor não-racional". Tese de Doutorado em Sociologia. Faculdade de Filosofia, Letras e Ciências Humanas, Universidade de São Paulo, São Paulo, 1996.

Simão, A. "O voto operário em São Paulo". Revista Brasileira de Estudos Políticos, Belo Horizonte, no $1,1956$.

Singer, A. Collor na periferia: a volta por cima do populismo? In: LAMOUNIER, B. (org.). De Geisel a Collor: o balanço da transição. São Paulo: Sumaré/Idesp, 1990.

. "Ideologia e voto no segundo turno da eleição presidencial de 1989". Dissertação de

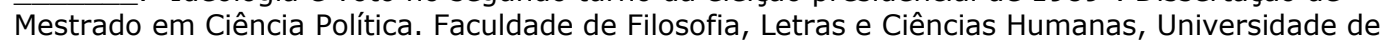
São Paulo, São Paulo, 1993.

. "Identificação ideológica e voto no Brasil: o caso das eleições presidenciais de 1989 e 1994". Tese de Doutorado em Ciência Política. Faculdade de Filosofia, Letras e Ciências Humanas, Universidade de São Paulo, São Paulo, 1998.

. Esquerda e direita no eleitorado brasileiro. São Paulo, Edusp, 2000.

SPECK, B. W.; BALBACHEVSKY, E. "Identificação partidária e voto. As diferenças entre petistas e peessedebistas". Opinião Pública, Campinas, vol. 22, no 3, p. 569-602, 2016.

Weffort, F. "Raízes sociais do populismo em São Paulo". Revista Civilização Brasileira, ano 1, n 2, p. 39-60, maio 1965 .

\section{Anexo metodológico}

Ao recorrermos ao modelo de regressão logística binária em nossa análise, foi preciso recodificar as variáveis para a aplicação dos testes estatísticos. Dessa maneira, no grupo de variáveis sociodemográficas, a variável renda familiar mensal foi categorizada a partir do valor do salário mínimo em cada período - R\$ 200,00 em 2002 e R\$ 724,00 em 2014 - e padronizada em seis faixas de renda familiar mensal; as variáveis escolaridade e faixa etária ${ }^{10}$ foram padronizadas em quatro categorias; e a variável religião, em três categorias ${ }^{11}$.

Sobre o grupo de variáveis de caráter identitário e de interesse por política, categorizamos a autolocalização ideológica em esquerda, centro e direita, sendo o "centro" adotado como referência para as demais categorias ${ }^{12}$. Em relação ao interesse por política, optamos por manter o padrão aplicado na onda de 2002, considerando três categorias: "nada interessado", "interessado ou

\footnotetext{
${ }^{10}$ No caso das faixas etárias, adotamos a sugestão já utilizada pelo Cesop em suas análises: de 16 a 24 anos; de 25 a 40 anos; de 41 a 64 anos; e 65 ou mais.

${ }^{11}$ Para as variáveis renda familiar mensal, escolaridade, sexo, faixa etária e religião, consideramos como referências as categorias "até 1 salário mínimo", "analfabeto", "masculino", "65 anos ou mais" e "outras religiões", respectivamente.

12 Nas ondas de 2002 e 2014, o Eseb aferiu a autolocalização ideológica dos respondentes a partir de uma escala de 0 a 10, em que 0 significa ser de esquerda e 10 ser de direita. Em nossa análise, categorizamos o posicionamento ideológico como sendo esquerda (de 0 a 3), centro (de 4 a 6 ) e direita (de 7 a 10).
} 
pouco interessado" e "muito interessado"13. No sistema dummy, as categorias "nenhum interesse", em 2002, e "nada interessado", em 2014, foram consideradas como referências das demais categorias.

O terceiro conjunto de variáveis é o das que possuem um caráter pragmático: a rejeição partidária, ser beneficiário do Bolsa Família, a avaliação retrospectiva do desempenho, a avaliação da situação econômica do país nos últimos 12 meses, a satisfação com o funcionamento da democracia, a adesão à democracia e o apontamento do maior problema do país.

Considerando a polarização entre PT e PSDB no cenário político nacional e estadual, selecionamos a variável rejeição partidária no intuito de averiguar seu impacto nas esferas federal e estadual. No entanto, assim como em relação à variável interesse por política, a mensuração da rejeição partidária se deu de forma diferente em 2002 e 2014, embora tenha conservado o mesmo sentido. Em 2002, o Eseb mensurou a rejeição partidária a partir das seguintes respostas: "votaria" e "não votaria". Em 2014, a mensuração da rejeição partidária foi aprimorada e apresentada sob o formato de escala de 0 a 10, em que 0 significa "rejeição" e 10 significa "não rejeição". Sendo assim, seguindo o mesmo modelo da mensuração do posicionamento ideológico, categorizamos essa variável como "rejeição" (de 0 a 3), "indiferentes" (de 4 a 6) e "não rejeição" (de 7 a 10). Na análise dos dados, sob o formato dummy, consideramos a categoria "indiferente" como aquela que servirá de referência para a análise das demais categorias ${ }^{14}$.

A variável que trata do beneficiário do Bolsa Família foi mantida em seu formato original em que as opções de respostas foram "sim" ou "não", sendo esta última a categoria de referência.

$\mathrm{Na}$ análise dos dados de 2002, consideramos a avaliação retrospectiva do governo de Fernando Henrique Cardoso a partir das categorias "ótimo", "bom", "regular bom", "regular ruim", "ruim" e "péssimo"; a satisfação com o funcionamento da democracia a partir das categorias "muito satisfeito", "satisfeito", "indiferente", "pouco satisfeito" e "nada satisfeito"; a adesão à democracia a partir das ideias de que ela "é sempre a melhor forma de governo" e de que, "em algumas situações, a ditadura é melhor que a democracia"; e o maior problema do país ${ }^{15}$ a partir das categorias "desemprego", "violência e segurança", "inflação", "corrupção", "educação", "saúde", "fome/pobreza/miséria", "desigualdade social e distribuição de renda", "salários e poder aquisitivo", "economia/dólar/crise econômica", "governo FHC e políticas adotadas", "drogas", "dívida externa", "má administração e políticos", "seca", "transporte", "desvalorização do real", "impostos altos" e "outros".

\footnotetext{
${ }^{13}$ O Eseb de 2014 mensurou o interesse por política a partir das seguintes categorias: "nada interessado", "pouco interessado", "interessado" e "muito interessado". Com o intuito de comparar a intensidade do interesse por política manifestado pelos respondentes, seguimos o modelo utilizado pela onda de 2002 e recodificamos a variável com as categorias "nenhum interesse", "interessado ou pouco interessado" e "muito interessado".

${ }^{14} \mathrm{Em}$ todos os testes de regressão aplicados foram considerados como ausentes os casos de "não sabe", "não respondeu" e "não se aplica".

${ }^{15}$ Essa variável foi aplicada apenas na onda de 2002. Todavia, optamos por mantê-la em nossa análise pelo fato de os testes estatísticos terem sinalizado para a forte relação desta com o voto. Em 2014, embora o Eseb tenha aprimorado a apresentação e a aplicação de algumas variáveis, a variável o maior problema do Brasil não foi aplicada e, portanto, não nos permitirá comparações de seu efeito nos períodos observados.
} 
Para os dados de 2014, utilizamos as mesmas categorias apresentadas originalmente pelo Eseb no que diz respeito à variável sobre avaliação do governo Dilma (no caso, as categorias "ótimo", "bom", "regular", "ruim" e "péssimo"). Em relação à avaliação da situação econômica do país nos últimos 12 meses, reagrupamos as categorias em "melhor", "igual" e "pior". A variável sobre satisfação com o funcionamento da democracia repete as categorias utilizadas na onda de 2002 e a variável relativa à adesão à democracia acrescenta a categoria "indiferente", além das outras duas também aplicadas em 2002.

Uma vez organizadas e recodificadas as categorias das variáveis independentes (sociodemográficas, identitárias e pragmáticas), testamos os seus efeitos sobre as variáveis dependentes do nosso modelo: os votos para presidente e para governador de São Paulo nas eleições de 2002 e 2014. Para sustentar nossa análise, também aplicamos os testes de quiquadrado, verossimilhança log $-2, \mathrm{R}^{2}$ Cox \& Snell e o $\mathrm{R}^{2}$ Nagelkerke, já que estes aferem a significância da relação entre as variáveis analisadas, além da qualidade e aceitabilidade do modelo ajustado no intuito de poder concluir o efeito das variáveis previsoras sobre as variáveis respostas. A partir desses testes consideramos o coeficiente $\beta$ enquanto uma indicação de como o sistema e os resultados obtidos se alterarão caso ocorra uma mudança na variável analisada; o valor da estatística de Wald, de quanto a mudança indicada por $\beta$ difere de 0 ; o grau de significância de cada variável; o $\operatorname{Exp}(\beta)$, ou odd ratio, que nos indica a relevância de cada variável analisada; e o cálculo de chances, como uma interpretação mais simples e didática do $\operatorname{Exp}(\beta)^{16}$.

\section{Resumo}

O comportamento eleitoral dos paulistas e dos brasileiros nas eleições de 2002 e 2014

A hipótese deste artigo é a de que existem distinções em relação ao comportamento eleitoral entre os eleitorados paulista e brasileiro. No caso, os aspectos sociodemográficos, quando comparados aos identitários e pragmáticos, influenciam menos o comportamento dos eleitores paulistas do que o dos brasileiros em geral. Em síntese, os paulistas tenderiam a considerar menos os aspectos sociais, econômicos e identitários e mais os aspectos pragmáticos. Para isso, aplicamos o modelo de regressão logística binária sobre os votos para presidente e para governador de São Paulo no $1^{\circ}$ turno das eleições de 2002 e 2014. A seleção de variáveis previsoras considerou algumas das que já foram e/ou ainda costumam ser indicadas por diversas pesquisas nacionais, além de outras sugeridas por este artigo, divididas em três grupos: variáveis sociodemográficas (renda familiar mensal, escolaridade, idade, sexo e religião), identitárias (interesse por política e posicionamento ideológico) e pragmáticas (rejeição partidária, beneficiário do Programa Bolsa Família, avaliação em relação ao governo, à economia e à democracia). Finalmente, acreditamos que este artigo possa contribuir como um estudo preliminar capaz de identificar aspectos e conjuntos de variáveis que explicam possíveis mudanças e tendências do comportamento político dos eleitorados paulista e brasileiro.

Palavras-chaves: comportamento político; eleitorado paulista; Eseb

\footnotetext{
16 Por se tratar de um modelo com extensa gama de variáveis e categorias testadas, optamos por apresentar nas tabelas apenas aquelas em que verificamos relações significativas e as destacamos no corpo do texto.
} 


\section{Abstract \\ The electoral behavior of Paulistas and Brazilians in the 2002 and 2014 elections}

The hypothesis presented in this work is that there are distinctions in electoral behavior between São Paulo's electorate and the general Brazilian electorate. This was noted when comparing sociodemographic aspects to identity and pragmatic ones. This comparison showed that sociodemographic aspects have a lower influence over the behavior of Paulista voters than over Brazilians in general. In short, the Paulistas would tend to consider social and economic aspects less and identity and pragmatic aspects more. In our analysis, we applied a binary logistic regression model on the votes for president and for governor of São Paulo in the first round of the elections in 2002 and 2014. In order to select the predictive variables for this study, we took into consideration not only some variables that were already and/or are still usually indicated by many national studies, but also other variables divided into three groups: 1) social and demographic variables (monthly family income, schooling, age, sex, and religion); 2) identity (interest in politics and ideological positioning); and pragmatic (partisan rejection, Bolsa Família beneficiary, evaluation and relation to government, economy, and democracy). Finally, we believe that this analysis, as a preliminary study, can contribute to identifying aspects and sets of variables that explain possible changes and trends in the political behavior of the Paulista and Brazilian electorates.

Keywords: political behavior; São Paulo electorate; Eseb

\section{Resumen}

El comportamiento electoral de paulistas y de brasileños en las elecciones de 2002 y 2014

La hipótesis que sigue es que hay diferencias en relación al comportamiento electoral entre el electorado de São Paulo y la de otros estados brasileños. En ese caso, los factores socio demográficos y los de la identidad en cuanto comparados con los pragmáticos, influyen menos en el comportamiento de los votantes Paulistas que en el de los brasileños en general. En resumen, los paulistas tienden a considerar menos los aspectos sociales, económicos e identitarios y más los aspectos pragmáticos. En nuestro análisis, aplicamos el modelo de regresión logística binaria en los votos para presidente y gobernador de São Paulo en la primera ronda de las elecciones de 2002 y 2014. La selección de las variables previsoras, consideró algunas de las cuales ya han sido y/o son generalmente indicadas por varias encuestas nacionales, así como otras sugeridas por este estudio, se dividieron en tres grupos: variables socio-demográficas (los ingresos mensuales de la familia, nivel educativo, edad, sexo y religión), identidades (interés en la política y la posición ideológica) y pragmática (rechazo, destinatario del Programa Bolsa Familia, la evaluación en relación al gobierno, a la economía y a la democracia). Por último, creemos que este análisis puede contribuir como un estudio preliminar capaz de identificar aspectos y conjuntos de variables que explican los posibles cambios y tendencias en el comportamiento político de los electorados de São Paulo y de Brasil.

Palabras clave: comportamiento político; electorado de São Paulo; Eseb

\section{Résumé}

Le comportement électoral à São Paulo et au Brésil pour les élections de 2002 et 2014

L'hypothèse de cet article est qu'il existe des distinctions en ce qui concerne le comportement électoral des électeurs de São Paulo par rapport à ceux du Brésil. Dans ce cas, les facteurs sociodémographiques, lorsqu' on les compare aux facteurs identitaires et pragmatiques, influencent moins le comportement des électeurs de São Paulo que celui des brésiliens en général. En fait, on aurait tendance, à São Paulo, à moins tenir compte des aspects sociaux, économiques et identitaires que des aspects pragmatiques. Dans l'analyse, nous avons appliqué le modèle de régression logistique binaire des votes pour le président et le gouverneur de l'état de São Paulo au $1^{\mathrm{er}}$ tour des élections de 2002 et de 2014. La sélection de variables prédictives en concerne quelques-unes qui 
ont été et/ou sont encore indiquées par plusieurs enquêtes nationales, outre celles suggérées dans cette étude, divisées en trois groupes: les variables sociodémographiques (le revenu familial, l'éducation, l'âge, le sexe et la religion), les variables identitaires (l'intérêt politique et le positionnement idéologique) et les variables pragmatiques (rejet du parti, bénéficiaire du Programme d'aide aux familles, évaluation du gouvernement, de l'économie et de la démocratie). Enfin, cette analyse pourrait contribuer comme une étude préliminaire afin d'identifier les aspects et les ensembles de variables qui expliquent les changements et les tendances possibles du comportement politique des électeurs de São Paulo et du Brésil.

Mots-clés: comportement politique; électorat de São Paulo apresentou as suas demandas sem politizá-las (Figura 1) e como o MBL politizou as demandas feitas em junho de 2013 (Figura 2) organizando um movimento contra a corrupção e contra a presidente Dilma Rousseff.; Eseb

Artigo submetido à publicação em 31 de março de 2016. Versão final aprovada em 10 de março de 2017. 